\title{
The Effects of Chemistry Variations in New Nickel-Based Superalloys for Industrial Gas Turbine Applications
}

\author{
SABIN SULZER @ (D, MAGNUS HASSELQVIST, HIDEYUKI MURAKAMI, \\ PAUL BAGOT, MICHAEL MOODY, and ROGER REED
}

\begin{abstract}
Industrial gas turbines (IGT) require novel single-crystal superalloys with demonstrably superior corrosion resistance to those used for aerospace applications and thus higher $\mathrm{Cr}$ contents. Multi-scale modeling approaches are aiding in the design of new alloy grades; however, the CALPHAD databases on which these rely remain unproven in this composition regime. A set of trial nickel-based superalloys for IGT blades is investigated, with carefully designed chemistries which isolate the influence of individual additions. Results from an extensive experimental characterization campaign are compared with CALPHAD predictions. Insights gained from this study are used to derive guidelines for optimized gas turbine alloy design and to gauge the reliability of the CALPHAD databases.
\end{abstract}

https://doi.org/10.1007/s11661-020-05845-7

(C) The Author(s) 2020

\section{INTRODUCTION}

NiCKEL-BASED superalloys have emerged as the materials of choice for high-temperature industrial gas turbine (IGT) applications due to their unique combination of resistance to loading under static, fatigue, and creep conditions, as well as to environmental degradation. ${ }^{[1]}$ Materials tailored to particular gas turbine specifications are required, as a simple adaptation or modification of aeroengine alloys cannot yield optimal results due to distinct design factors including weight restriction, operating time, fuel quality, and cyclic duty. ${ }^{[2]}$

In Figure 1, a proposed design space for new, improved IGT alloys is compared with existing commercial compositions. The latter tend to either possess (1) a high $\mathrm{Al} / \mathrm{Cr}$ ratio and exhibit good creep properties, but weak corrosion resistance, having been developed for aerospace applications, or (2) a low $\mathrm{Al} / \mathrm{Cr}$ ratio,

SABIN SULZER is with the Hilti Corporation, Feldkircherstraße 100, 9494, Schaan, Liechtenstein and also with the Department of Materials, Univerity of Oxford, Parks Road, Oxford, OX1 3PH, UK. Contact e-mail: sabin.sulzer@hilti.com. MAGNUS HASSELQVIST is with the Turbine Group, Siemens Industrial Turbomachinery AB, 61283 Finspång, Sweden. HIDEYUKI MURAKAMI is with the Research Centre for Structural Materials, National Institute for Materials Science, 1-2-1 Sengen, Tsukuba, 305-0047, Japan and also with the Department of Nanoscience and Nanoengineering, Waseda University, 3-4-1 Okubo, Shinjuku-ku, Tokyo, 169-8555, Japan. PAUL BAGOT, MICHAEL MOODY and ROGER REED are with the Department of Materials, University of Oxford.

Manuscript submitted March 8, 2020.

Article published online June 22, 2020 resulting in IGT environment suitability, but at the cost of lower strength. 'Classical' IGT alloys like IN-792 $2^{[3]}$ and Mar-M247 $7^{[4]}$ were developed more than 45 years ago when turbine inlet temperature levels were much lower. As such, only few compositions satisfy both requirements and populate the envisioned area above 13.2 at. pet $\mathrm{Cr}$ and 8.5 at. pet $\mathrm{Al}$.

A recent foray into this space was made with the development of the single-crystal alloy STAL15SX ${ }^{[5-7]}$ and of the conventionally cast derivative STAL15CC. ${ }^{[8,9]}$ These alloys contain 17.8 at. pct $\mathrm{Cr}$ for high hot corrosion resistance and also provide excellent oxidation resistance due to their ability to form a continuous $\mathrm{Al}_{2} \mathrm{O}_{3}$ surface layer at high temperatures. This enables both high turbine inlet temperatures and high fuel flexibility, while minimizing the risk of component failure should protective thermal barrier coatings crack. STAL15SX possesses sufficient creep strength for use in IGT first-stage blades, while STAL15CC is aimed at hot stator components.

There is an obvious possibility to design further derivatives at lower $\mathrm{Cr}$ and higher $\mathrm{Al}$ contents. This would increase creep and oxidation resistance, while retaining $\mathrm{Cr}$ levels above the commonplace threshold of 13.5 at. pct for sufficient hot corrosion resistance. ${ }^{[10]}$ Within this scope, multi-scale modeling approaches have been successfully developed and applied to design tailored nickel-based superalloys for turbine blade [11-13] $^{[3}$ and turbine disk applications. ${ }^{[13,14]}$ However, an important caveat is that several key input parameters are derived from thermodynamic CALPHAD methods, which in turn depend on commercial parameter 


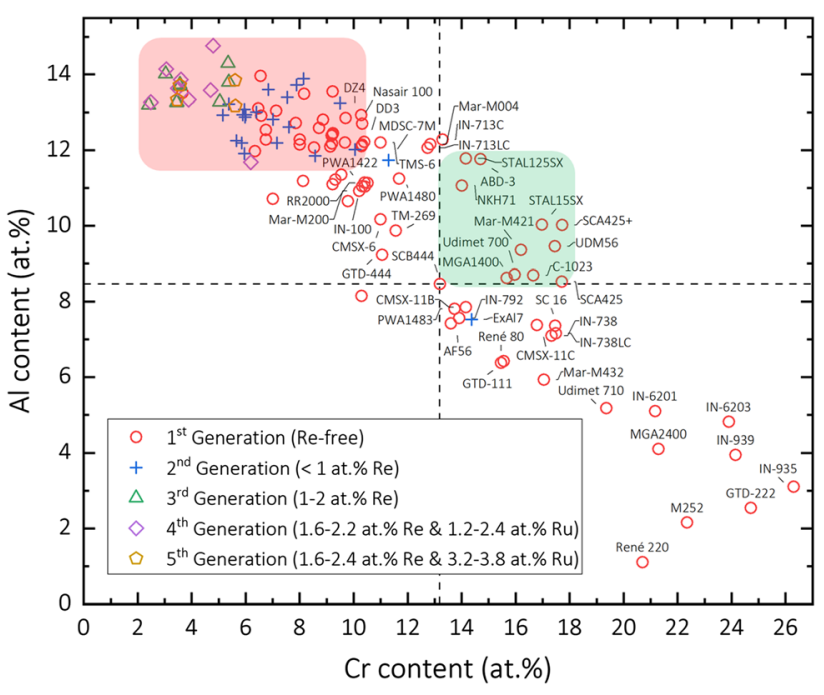

Fig. 1-Comparison of the proposed design space for new IGT superalloys (green rounded rectangle) with the general compositional space occupied by Re-containing aerospace alloys (red rounded rectangle). This dataset was compiled from literature published as journal articles or patents; therefore, slight differences to versions sold commercially may occur. Alloys containing more than 9 at. pet $\mathrm{Cr}$ are labeled accordingly (Color figure online).

databases. The reliability and validity of modeling results are dictated by the accuracy of these databases and any significant errors will give rise to false conclusions regarding optimal alloy compositions. This issue is especially acute for new regions of the alloy design space, such as the one considered here, since experimental data will be scarce or missing altogether. Thus, it is imperative to improve and expand the performance of CALPHAD tools and to gain a better understanding of the influence of chemistry on thermochemical and physical alloy properties and on microstructure.

The present work aims to remedy this situation by investigating a set of trial IGT alloys with carefully designed chemistries, which isolate the influence of individual additions. Results from an extensive experimental characterization campaign are compared with CALPHAD predictions using the Thermo-Calc software package. Insights gained from this study are used to derive guidelines for optimized IGT alloy design and to improve the reliability of CALPHAD techniques.

\section{EXPERIMENTAL METHOD}

\section{A. Material}

A set of six trial alloys, denoted in the following as SX1 to SX6, was pre-alloyed either from pure elements (Al, Cr, Co, Fe, Ni, Si, Ti) or from binary Ni-X alloys for refractory metals (Ni-Hf, Ni-Mo, Ni-Ta, Ni-W). Batches of $120 \mathrm{~g}$ were weighed, arc-melted under $\mathrm{Ar}$ using an Edmund Bühler AM 500 arc melter, and poured into water-cooled copper molds. Nominal chemical compositions in at. pct are presented in Table I. The base composition of the investigated alloy series, denoted as SX1, was derived from STAL15SX to the design point of 14.2 at. pet $\mathrm{Cr}$ and 12 at. pct Al. Four compositions were designed to assess the influence of adding 0.3 at. pet $\mathrm{Hf}$ (SX2), 5.2 at. pet $\mathrm{Fe}$ (SX3), and 1 at. pct $\mathrm{Si}$ (SX6) and of increasing the Co content from 5 to 10 at. pct (SX5). Finally, a composition with lower $\mathrm{Al}$ and Ta levels and containing 2.9 at. pet Ti (SX4) was also included as a 'combination' between the base alloy and IN-792.

\section{B. Differential Scanning Calorimetry}

Differential scanning calorimetry (DSC) testing was carried out using a Netzsch DSC 404 F1 Pegasus. Measurements were carried out at heating/cooling rates of $10{ }^{\circ} \mathrm{C} / \mathrm{min}$ under a high purity Ar atmosphere at a purge flow rate of $40 \mathrm{~mL} / \mathrm{min}$. PtRh crucibles with PtRh lids and thin-walled $\mathrm{Al}_{2} \mathrm{O}_{3}$ liners were used in combination with a high-accuracy sample carrier system with type $\mathrm{S}$ thermocouples. Disk specimens of $3 \mathrm{~mm}$ diameter and $1 \mathrm{~mm}$ thickness were manufactured by wire-guided electro-discharge machining (EDM). Both circular surfaces were polished down to 4000 grit silicon carbide grinding paper to achieve good thermal contact with the sensor. Each specimen was ultrasonically cleaned in ethanol and weighed before the test.

For each test, two heating/cooling cycles were performed between $700{ }^{\circ} \mathrm{C}$ and $1450{ }^{\circ} \mathrm{C}$ to assess the influence of prior melting/solidification and of reduced segregation on the second cycle. To equalize the temperature in the system, constant temperature segments of 15 minutes duration were added between ramp steps. Following the ASTM method, three measurements were carried out as part of each test: (1) a baseline measurement with an empty sample pan, (2) a calibration measurement with a synthetic sapphire disk of known mass and heat capacity, and (3) a sample measurement with the actual superalloy disk. The reference pan remained empty during all three runs. Finally, changes in alloy heat capacity, $C_{\mathrm{p}}$, with temperature, $T$, were calculated using the Netzsch Proteus analysis program.

\section{Heat Treatment and Chemical Analysis}

Preliminary DSC studies on as-received material gave an indication of the $\gamma^{\prime}$ solvus and solidus temperatures for each alloy. Using this information, solutioning heat treatments were carried out to reduce microsegregation between dendrite core and interdendritic regions, while avoiding incipient melting. Samples were placed in a pre-heated furnace at $1170{ }^{\circ} \mathrm{C}$. The temperature was then slowly ramped up at a constant rate of $0.1^{\circ} \mathrm{C} / \mathrm{min}$ up to $20{ }^{\circ} \mathrm{C}$ below the expected solidus, following the method proposed by Hegde et al. ${ }^{[15]}$ After reaching the peak temperature, specimens were cooled down at $10{ }^{\circ} \mathrm{C} / \mathrm{min}$ to $850{ }^{\circ} \mathrm{C}$ and were then removed from the furnace and air-cooled. Subsequent primary and secondary aging heat treatments were chosen at $1120^{\circ} \mathrm{C}$ for 4 hours and $845{ }^{\circ} \mathrm{C}$ for 24 hours, both completed by air-cooling. 
Table I. Chemical Compositions of the Alloys in Fully Heat-Treated Condition

\begin{tabular}{|c|c|c|c|c|c|c|c|c|c|c|c|c|}
\hline \multirow[b]{2}{*}{ Alloy } & \multirow[b]{2}{*}{ Method } & \multicolumn{11}{|c|}{ Chemical Composition (At. Pct) } \\
\hline & & $\mathrm{Ni}$ & $\mathrm{Cr}$ & $\mathrm{Co}$ & Mo & $\mathrm{W}$ & $\mathrm{Al}$ & $\mathrm{Ti}$ & $\mathrm{Ta}$ & Hf & $\mathrm{Si}$ & $\mathrm{Fe}$ \\
\hline \multirow[t]{3}{*}{ SX1 (Base) } & nominal & 64.2 & 14.2 & 4.99 & 0.92 & 1.12 & 12 & 0 & 2.6 & 0 & 0 & 0 \\
\hline & ICP-OES & 64.6 & 13.9 & 4.9 & 0.89 & 1.08 & 12.1 & 0 & 2.5 & 0 & 0.06 & 0.02 \\
\hline & EPMA & 63.5 & 14.8 & 5.2 & 0.81 & 1.11 & 11.9 & & 2.72 & & & \\
\hline \multirow[t]{3}{*}{$\mathrm{SX} 2(+\mathrm{Hf})$} & nominal & 63.6 & 14.3 & 5.02 & 0.93 & 1.13 & 12.1 & 0 & 2.62 & 0.33 & 0 & 0 \\
\hline & ICP-OES & 64.9 & 13.3 & 4.86 & 1.02 & 0.90 & 11.8 & 0 & 2.82 & 0.34 & 0.08 & 0.02 \\
\hline & EPMA & 64.3 & 14.5 & 5.21 & 0.88 & 1.04 & 10.9 & & 2.8 & 0.32 & & \\
\hline \multirow[t]{3}{*}{$\mathrm{SX} 3(+\mathrm{Fe})$} & nominal & 59.1 & 14.1 & 4.98 & 0.92 & 1.12 & 12 & 0 & 2.6 & 0 & 0 & 5.25 \\
\hline & ICP-OES & 58.4 & 13.9 & 4.96 & 0.89 & 1.08 & 11.7 & 0 & 2.5 & 0 & 0.06 & 6.61 \\
\hline & EPMA & 59.1 & 15 & 5.09 & 0.77 & 1.07 & 11 & & 2.63 & & & 5.3 \\
\hline \multirow[t]{3}{*}{$\mathrm{SX} 4(+\mathrm{Ti})$} & nominal & 63.5 & 14 & 4.93 & 0.91 & 1.11 & 10.8 & 2.91 & 1.93 & 0 & 0 & 0 \\
\hline & ICP-OES & 63.8 & 14 & 4.89 & 0.89 & 1.09 & 10.6 & 2.89 & 1.85 & 0 & 0.06 & 0.03 \\
\hline & EPMA & 62.9 & 14.7 & 5.09 & 0.76 & 1.07 & 10.2 & 3.27 & 2.03 & & & \\
\hline \multirow[t]{3}{*}{$\mathrm{SX} 5(++\mathrm{Co})$} & nominal & 59.2 & 14.2 & 9.98 & 0.92 & 1.12 & 12 & 0 & 2.6 & 0 & 0 & 0 \\
\hline & ICP-OES & 58.8 & 14.1 & 10.3 & 0.91 & 1.1 & 12.1 & 0 & 2.49 & 0 & 0.06 & 0.03 \\
\hline & EPMA & 58.6 & 14.8 & 10.3 & 0.82 & 1.1 & 11.8 & & 2.67 & & & \\
\hline \multirow[t]{3}{*}{$\mathrm{SX} 6(+\mathrm{Si})$} & nominal & 64.4 & 14.2 & 5 & 0.92 & 1.12 & 10.7 & 0 & 2.61 & 0.03 & 1.05 & 0 \\
\hline & ICP-OES & 66.2 & 13.2 & 4.44 & 0.92 & 1.11 & 10.7 & 0 & 2.3 & 0.02 & 1.05 & 0.03 \\
\hline & EPMA & 64.8 & 14 & 5.14 & 0.85 & 1.14 & 10.6 & & 2.76 & 0.02 & 0.74 & \\
\hline
\end{tabular}

Nominal values are compared with measurements from ICP-OES and EPMA analyses. Note that elements not expected in an alloy were omitted for EPMA.

The chemistries of fully heat-treated specimens were checked at an independent laboratory using inductively coupled plasma optical emission spectrometry (ICP-OES) for metallic elements and combustion analysis for $\mathrm{C}$ and $\mathrm{S}$ impurities. To further assess the remaining degree of microsegregation, chemistries were also checked on polished specimens by electron probe microanalysis (EPMA) using a JEOL JXA 8800 Superprobe equipped with four wavelength-dispersive X-ray spectrometers (WDS) for parallel detection of elements. Line scans of 200 points were carried out at a spacing of $10 \mu \mathrm{m}$, a probe diameter of $10 \mu \mathrm{m}$, an accelerating voltage of $25 \mathrm{keV}$, a beam current of $32 \mathrm{nA}$, and a dwell time for each point of $100 \mathrm{~ms}$. The diffracting crystals used for WDS were LIF for Ni, Co, W, Ta, Hf, and Fe, PETJ for $\mathrm{Cr}, \mathrm{Mo}$, and $\mathrm{Ti}$, and TAP for $\mathrm{Al}$ and $\mathrm{Si}$. X-ray counts were converted to concentration values using standard correction procedures and signals from pure element standards. Average compositions obtained from ICP-OES and EPMA are shown in Table I below the nominal values.

\section{Electron Microscopy}

Metallographic preparation was carried out on a Struers Tegramin-25 system down to $1 \mu \mathrm{m}$ diamond suspension. An optimal finish was achieved by polishing for 5 minutes with a 1 to 1 mixture of Struers OP-S 0.04 $\mu \mathrm{m}$ colloidal silica suspension and water on a Struers MD-Chem polishing cloth. Specimens were cleaned in an ultrasonic bath with acetone and then with ethanol. Backscatter electron (BSE) images of fully heat-treated microstructures were obtained using a Zeiss Merlin field emission gun (FEG) SEM operating at an accelerating voltage of $10 \mathrm{keV}$ and a probe current of $500 \mathrm{pA}$. The working distance was set at $8.5 \mathrm{~mm}$ to yield optimal energy-dispersive X-ray spectroscopy (EDX) results using an Oxford Instruments $\mathrm{X}$-Max ${ }^{\mathrm{N}}$ silicon drift detector with a size of $150 \mathrm{~mm}^{2}$. EDX data were processed using the TruMap function of the Oxford Instruments AZtec 3.3 software package to eliminate artifacts, correct background and peak overlaps, and enhance compositional variations.

\section{E. Atom Probe Tomography}

Matchsticks of $0.5 \times 0.5 \times 2 \mathrm{~mm}^{3}$ were manufactured by EDM from fully heat-treated material. Sharp tips for atom probe tomography (APT) with a radius below 100 $\mathrm{nm}$ were produced in a two-stage electro-polishing process. The matchsticks were first coarse-polished in a solution of $10 \mathrm{vol}$ pet perchloric acid in acetic acid at a voltage of 12 to $20 \mathrm{VDC}$ and then fine-polished in a solution of $2 \mathrm{vol}$ pct perchloric acid in 2-butoxyethanol at 8 to 12 VDC. APT data were collected using a CAMECA local electrode atom probe (LEAP) 5000 XR at a specimen base temperature of $50 \mathrm{~K}$ and an ambient gauge pressure of less than $10^{-10} \mathrm{~Pa}$. Samples were run in laser-assisted mode with an ultraviolet laser wavelength of $355 \mathrm{~nm}$, a pulse energy of $50 \mathrm{pJ}$, a pulse frequency of $125 \mathrm{kHz}$, and a constant ion detection rate of 0.5 pct. 3D reconstructions were generated using the CAMECA IVAS 3.8.2 software package. Peak overlaps of multiple elemental species were deconvolved using the standard IVAS decomposition parameters.

\section{F. CALPHAD Predictions}

Throughout the present study, experimental results are compared with predictions made using version $2019 \mathrm{~b}$ of the Thermo-Calc software package and two associated databases for nickel-based superalloys - $\mathrm{TCNi}$, provided 
by Thermo-Calc Software AB, and TTNi8, provided by ThermoTech Ltd. The chemical compositions measured by ICP-OES were used as inputs. Phase diagrams were generated between $600{ }^{\circ} \mathrm{C}$ and $1400{ }^{\circ} \mathrm{C}$. Equilibrium phase compositions were calculated at the final aging temperature of $845{ }^{\circ} \mathrm{C}$. In both cases, a simplified three-phase system consisting of $\gamma, \gamma^{\prime}$, and liquid at high temperatures was assumed and all other phases were suspended. SEM results support this assumption, as only insignificant levels of small MC carbides and no topologically close-packed (TCP) phases were observed after heat treatment.

\section{RESULTS}

\section{A. Alloy Microstructure}

Chemical compositions determined by ICP-OES and EPMA are in good overall agreement with nominal values. Trace levels of Fe were detected, but no other impurities are present. Furthermore, EPMA line scans show little variation across the samples, implying good homogenization and low microsegregation after the heat treatment. Nonetheless, some discrepancies can be noted; the levels of $\mathrm{Cr}$ in SX2 and SX6, Co in SX6, W in SX2, and Ta in SX6 are somewhat lower than intended, while the levels of Ta in SX2 and Fe in SX3 are higher.

The microstructures shown in Figure 2 are characteristic of IGT superalloys and are composed of cuboidal, secondary $\gamma^{\prime}$ precipitates with side lengths on the order of $1 \mu \mathrm{m}$ and spherical, tertiary $\gamma^{\prime}$ particles with diameters on the order of $10 \mathrm{~nm}$, embedded in the $\gamma$ matrix. Secondary particles form after the homogenization step during cooling from around $1260^{\circ} \mathrm{C}$, while tertiary ones precipitate during the subsequent aging heat treatments at $1120{ }^{\circ} \mathrm{C}$ and $845{ }^{\circ} \mathrm{C}$. Secondary precipitate morphology varies between the alloys and appears more cuboidal for SX2, SX3, SX5, and SX6 and more rounded for SX1 and SX4. The substitution of Ta for $\mathrm{Ti}$ in SX4 results in a marked reduction in contrast between $\gamma$ and $\gamma^{\prime}$, as the heavy Ta makes precipitates appear brighter in BSE micrographs.

Particle size distributions were analyzed using the image processing software package MIPAR. Cross-sectional area fractions comprising both secondary and tertiary $\gamma^{\prime}$ were measured for each BSE micrograph. These can be considered equal to $\gamma^{\prime}$ volume fractions from a stereological standpoint as long as the precipitates do not have a preferred orientation. ${ }^{[16]}$ Values obtained by averaging the results from at least five micrographs are shown in Table II, along with Thermo-Calc predictions for equilibrium conditions at $845^{\circ} \mathrm{C}$.

EDX maps of elements added to the base composition of SX1 are presented in Figure 3. Hf and Ti are found to partition preferentially to $\gamma^{\prime}$, whereas $\mathrm{Fe}$ and $\mathrm{Co}$ are enriched in $\gamma$. EDX results for $\mathrm{Si}$ are inconclusive, in part due to peak overlaps with the Ta largely present in $\gamma^{\prime}$, as shown for the SX1 reference.

\section{B. Phase Transition Temperatures}

\section{Interpreting $C_{p}-T$ curves from $D S C$}

Curves of heat capacity illustrated in Figure 4 reveal several transitions with increasing temperature. Between $700{ }^{\circ} \mathrm{C}$ and $1100{ }^{\circ} \mathrm{C}$, there is a gradual increase in $C_{\mathrm{p}}$ due to coarsening of the $\gamma^{\prime}$ phase. ${ }^{[17,18]}$ This is followed by a gradual dissolution of $\gamma^{\prime}$ into the $\gamma$ matrix, which culminates in a peak at around $1200{ }^{\circ} \mathrm{C}$. Once all precipitates have dissolved, a single-phase plateau regime is observed up to about $1300{ }^{\circ} \mathrm{C}$, at which point melting initiates and gives rise to a strong endothermic peak. The melting stage concludes at around $1350{ }^{\circ} \mathrm{C}$
SX1

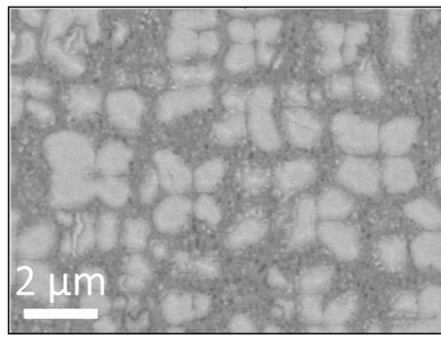

SX4

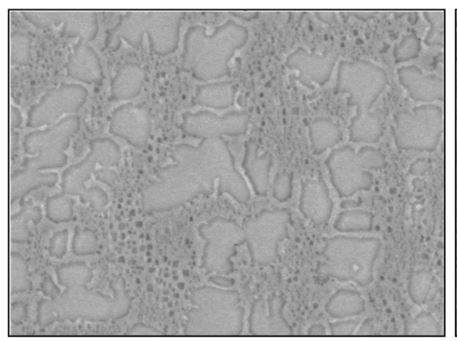

SX2

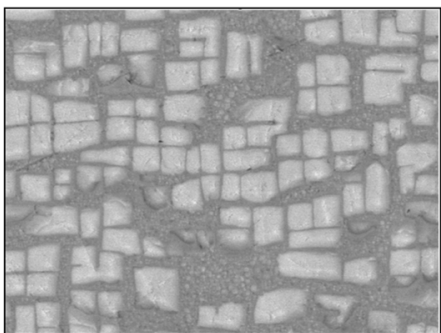

SX5

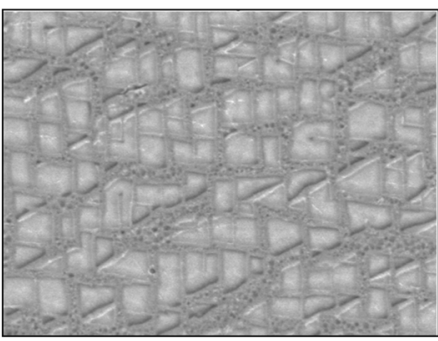

SX3

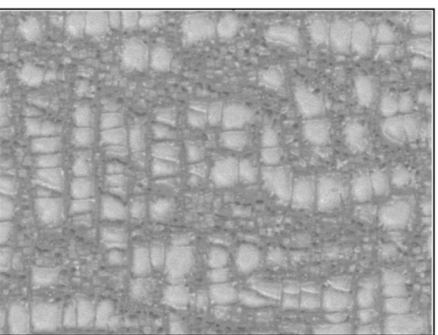

SX6

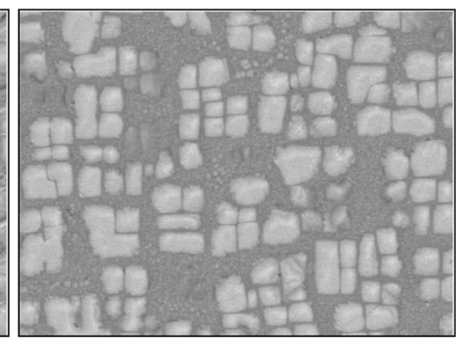

Fig. 2-SEM micrographs of the trial IGT alloys in fully heat-treated condition. The illustrated scale bar applies to all images. 
and $C_{\mathrm{p}}$ values return to similar levels to the beginning of the test.

Significant differences are observed between heating/cooling curves given the dynamic nature of the DSC technique. During heating, transitions take place at higher temperatures due to instrument lag. Conversely, data from cooling steps are significantly affected by undercooling effects which suppress transitions and cause them to occur more abruptly at lower temperatures. ${ }^{[19,20]}$ Consequently, eutectic reactions, which produce a weaker signal, are only detected during cooling, with distinct peaks appearing at $1240{ }^{\circ} \mathrm{C}$ for SX2 and at $1255{ }^{\circ} \mathrm{C}$ for SX4. Within the scope of comparing experimental data with ideal CALPHAD predictions, undercooling effects can lead to significant discrepancies of up to $20^{\circ} \mathrm{C} .^{[19,21]}$ This is especially true for alloys lacking grain boundary elements like $\mathrm{C}$ or $\mathrm{B}$, which would otherwise reduce undercooling by precipitating carbides or borides as nucleation points. ${ }^{[20]}$ Finally, differences can also be noted between the first and second heating/cooling steps. Owing to homogenization of the material during the first cycle, the magnitude of endothermic/exothermic peaks during dissolution/precipitation decreases, as seen in Figure 5.

Table II. Comparison of Average $\gamma^{\prime}$ Volume Fractions Estimated from SEM Micrographs with Thermo-Calc Predictions

\begin{tabular}{llcc}
\hline & \multicolumn{3}{c}{$\gamma^{\prime}$ Volume Fraction (Pct) } \\
\cline { 2 - 4 } Alloy & SEM & TCNi8 & TTNi8 \\
\hline SX1 & $59.2 \pm 1.6$ & 57.8 & 57.8 \\
SX2 & $56.2 \pm 1.4$ & 59.7 & 59.5 \\
SX3 & $51.5 \pm 1.9$ & 48.3 & 51.0 \\
SX4 & $62.7 \pm 2.1$ & 60.8 & 62.6 \\
SX5 & $58.5 \pm 1.9$ & 52.4 & 56.5 \\
SX6 & $54.4 \pm 1.3$ & 50.7 & 51.0 \\
\hline
\end{tabular}

Interpreting $C_{\mathrm{p}}-T$ curves to extract transition temperatures remains a matter of debate given the sluggish nature of solid state transitions. Sponseller ${ }^{[19]}$ recommends taking the $\gamma^{\prime}$ solvus as the 'recovery point' in a $C_{\mathrm{p}}-T$ curve, at which the signal returns to the baseline during heating or departs from it during cooling. The argument for this choice is that the location of the endothermic/exothermic peak is not only influenced by the actual location of the $\gamma^{\prime}$ solvus, but also by microsegregation between dendrite cores and interdendritic regions and by heating/cooling rate effects. However, Burton ${ }^{[21]}$ argues that peak temperatures are more indicative of the solvus, as the locations of 'recovery points' will be affected by instrument lag and by the finite sample size. In the present work, this latter interpretation is preferred and the $\gamma^{\prime}$ solvus is reported as the observed endothermic peak of dissolution during the second heating. In like manner, following Quested et al., ${ }^{[18]}$ the liquidus temperature is reported as the endothermic melting peak. Finally, following Chap$\operatorname{man}^{[20]}$ and Quested et al. ${ }^{[18]}$ the solidus temperature is determined by extrapolating the $C_{\mathrm{p}}-T$ baseline until it meets the slope of the front of the endothermic melting peak during second heating. These temperatures were evaluated using the built-in 'peak' and 'onset' functions of the Netzsch Proteus analysis program.

2. Effects of chemistry on the heat treatment window

Experimentally determined transition temperatures are compared with Thermo-Calc predictions in Table III. Both databases give accurate estimates of liquidus temperatures, with differences of $10{ }^{\circ} \mathrm{C}$ or less. DSC results tend to lie between TTNi8 values, which slightly underestimate the liquidus, and TCNi8 values, which slightly overestimate it. Solidus predictions show less agreement, with both databases largely underestimating experimental results. Discrepancies on the order of $10{ }^{\circ} \mathrm{C}$ to $20^{\circ} \mathrm{C}$ can be attributed to heating rate effects and to the challenging curve analysis when determining the 'onset' of melting. Overall, solidus values from
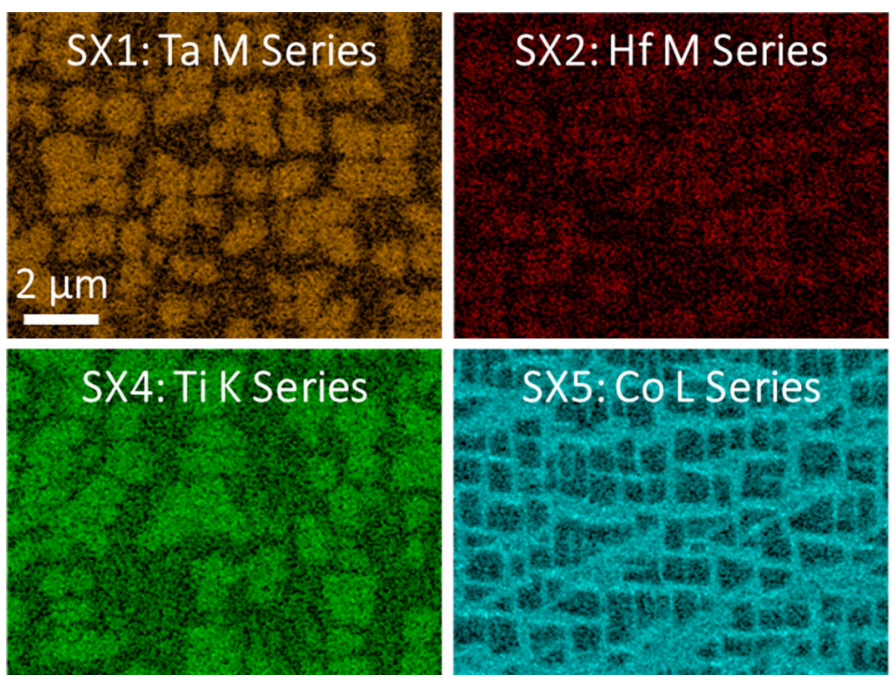

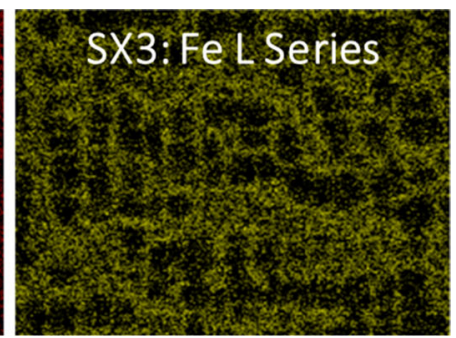

SX6:Si K Series

Fig. 3-EDX maps showing the preferential partitioning of the additions in alloys SX2-SX6. The illustrated scale bar applies to all images. 


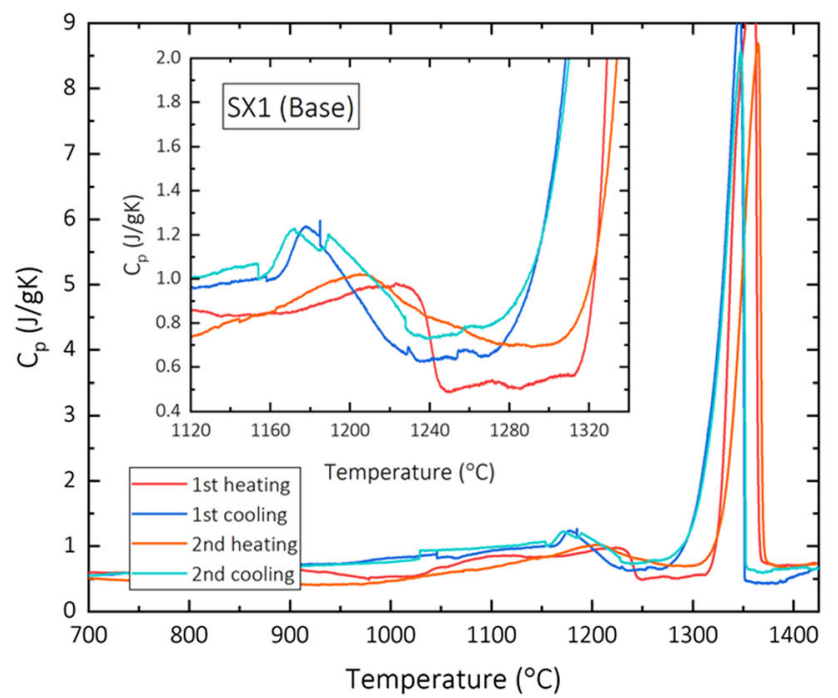

(a)

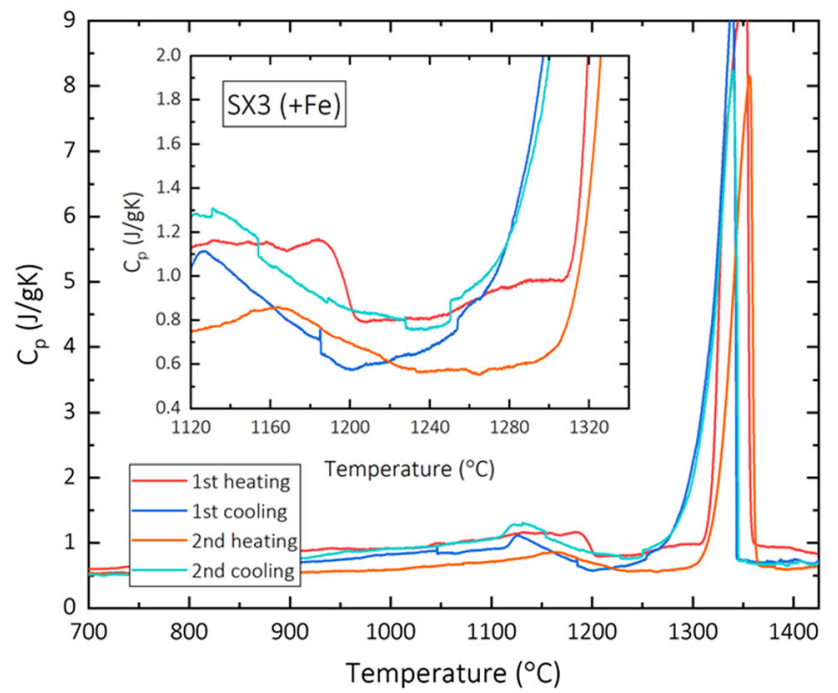

(c)

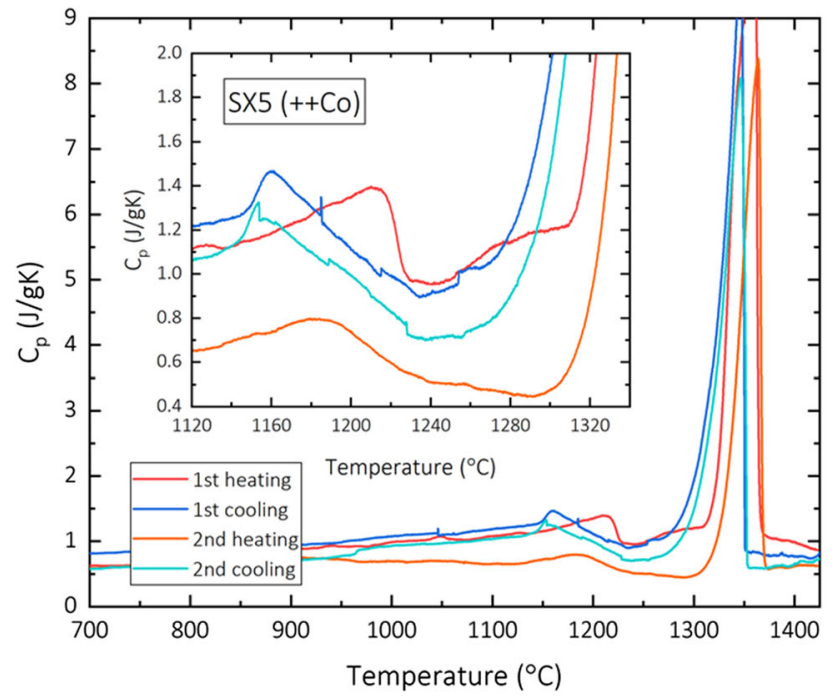

(e)

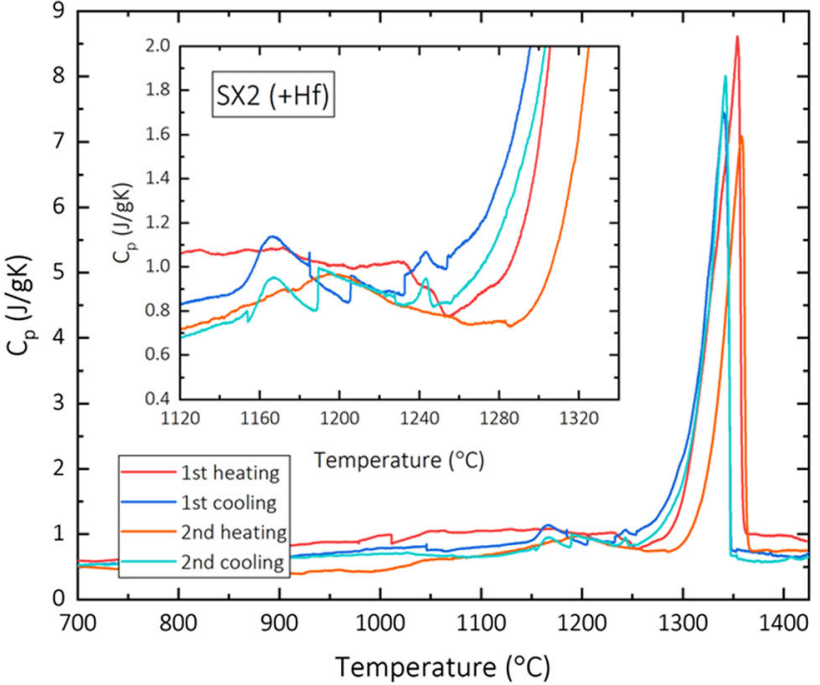

(b)

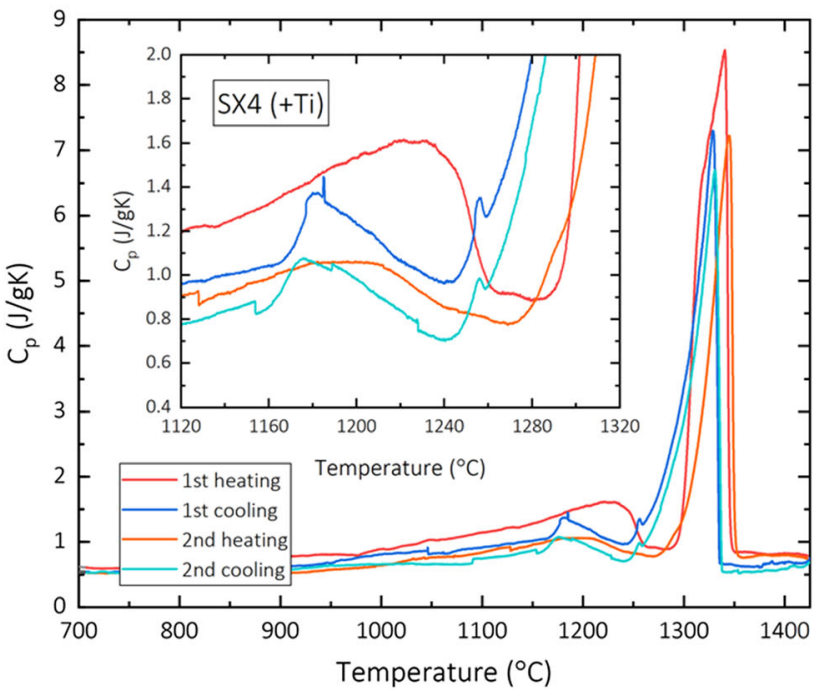

(d)

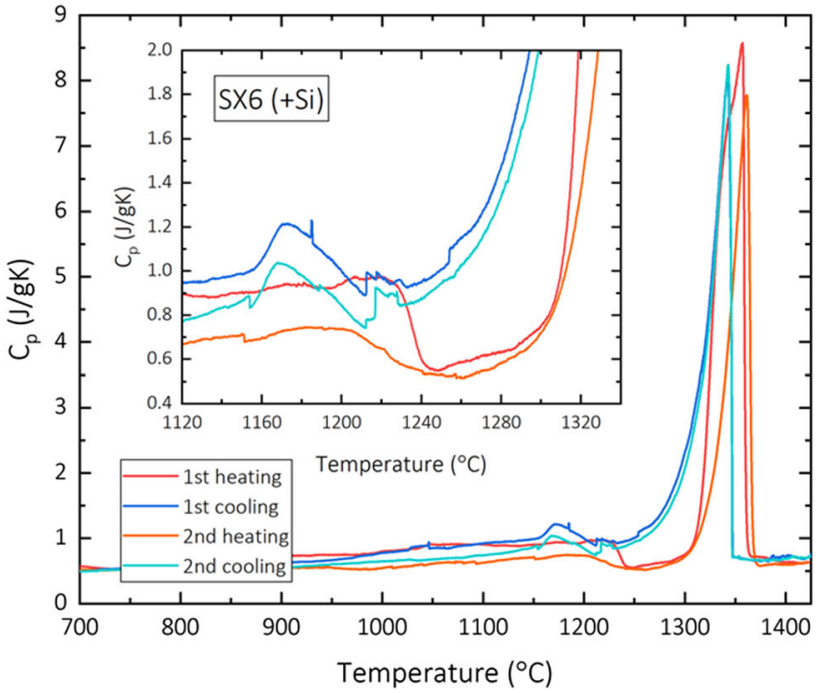

(f)

Fig. 4-(a) through $(f)$ Calculated changes in heat capacity, $C_{\mathrm{p}}$, with temperature, $T$, for the six trial alloys. Two heating/cooling stages were carried out in each DSC test. Insets show enlarged views of the heat treatment window sections. 
TCNi8 are closer to DSC data. Conversely, TTNi8 predictions for the $\gamma^{\prime}$ solvus show better agreement with experiments. TCNi8 strongly overestimates the solvus, even though non-equilibrium DSC results from heating

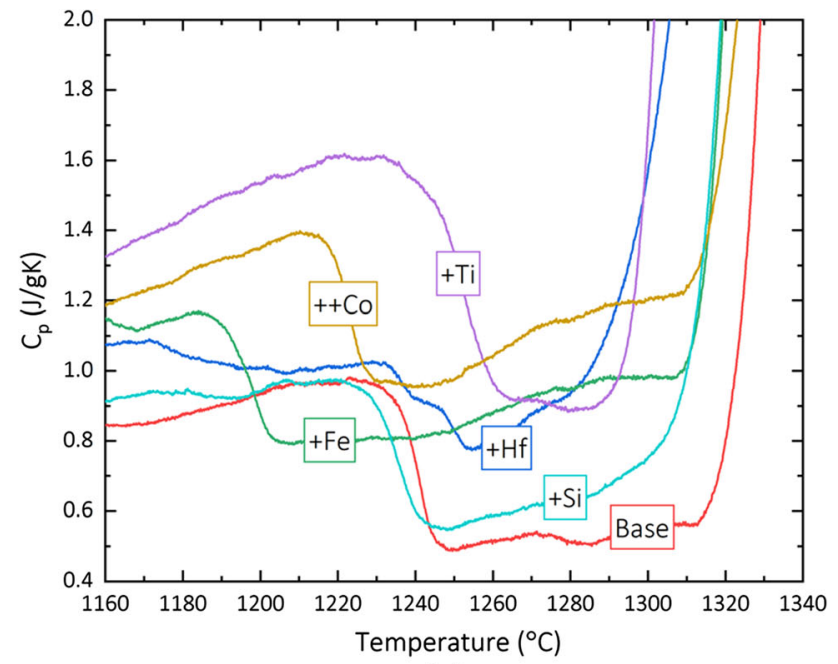

(a)

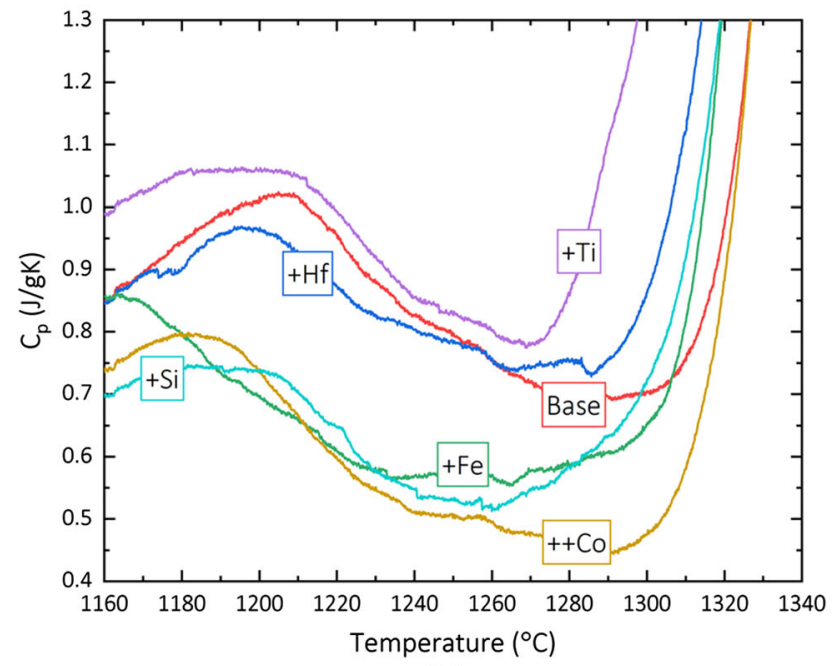

(b)

Fig. 5-Comparison of heat treatment window sections obtained during $(a)$ the first and $(b)$ the second heating stage. stages would be expected to yield higher values. The heat treatment window (HTW), obtained as the difference between solidus and $\gamma^{\prime}$ solvus, is a key alloy design feature. ${ }^{[1]}$ It provides a measure for the potential of post-casting heat treatments, which should ideally allow for a full homogenization in the single-phase $\gamma$ regime without any incipient melting. The best estimates of experimental HTWs are obtained by combining $\gamma^{\prime}$ solvus predictions from TTNi8 and solidus predictions from TCNi8.

Effects of chemistry changes on HTWs are presented in Figure 5 using data from the first and second heating stages. Comparisons are made to Thermo-Calc phase diagrams in Figure 6, using TTNi8 and TCNi8, respectively, to estimate changes in $\gamma^{\prime}$ and liquid molar fractions with temperature.

The addition of 0.34 at. pct $\mathrm{Hf}$ in SX2 significantly decreases the solidus temperature, while having little impact on the solvus. This is in good agreement with previous reports of $\mathrm{Hf}$ acting as a strong melting-point depressant and restricting the HTW.$^{[19,21,22]}$ Nonetheless, the same reports also indicate that $\mathrm{Hf}$ additions up to around 0.3 at. pct raise the solvus temperature due to the preferential partitioning of $\mathrm{Hf}$ to the $\gamma^{\prime}$ phase, ${ }^{[21,23]}$ also observed in the EDX maps of Figure 3. This discrepancy can be attributed to the lower level of $\mathrm{W}$ in SX2 compared with the nominal composition, as $\mathrm{W}$ is also known to raise the $\gamma^{\prime}$ solvus. ${ }^{[19,24]}$ It should be noted that Thermo-Calc correctly captures the reduced HTW as well as the tapered slope for the remaining liquid fraction during the final stages of solidification, as observed in Figure 6. Studies on hot tearing susceptibility of superalloys have shown that adding $\mathrm{Hf}$ increases the time available for liquid feeding and for stress relaxation, thus improving castability. ${ }^{[25,26]}$

A similar HTW reduction is observed for alloy SX4, in which 1.5 at. pct $\mathrm{Al}$ and 0.65 at. pct Ta are substituted with 2.9 at. pct Ti. Differential thermal analysis work by Sponseller ${ }^{[19]}$ showed that $\mathrm{Ta}$ and $\mathrm{Ti}$ are more potent than $\mathrm{Al}$ at raising the solvus and lowering the solidus and liquidus temperatures. A comparison of model IGT alloys with carefully controlled chemistries revealed that the liquidus decreases at a rate of $-6.6^{\circ} \mathrm{C} /$ at. pct $\mathrm{Al}$, $-13.3{ }^{\circ} \mathrm{C} /$ at. pet $\mathrm{Ti}$, and $-17.3{ }^{\circ} \mathrm{C} /$ at. pet $\mathrm{Ta}$, respectively ${ }^{[19]}$ in agreement with the present results for SX4. Thermo-Calc correctly predicts the reduced

Table III. Comparison of DSC Experimental Results with Thermo-Calc Modeling Predictions for $\gamma^{\prime}$ Solvus, Solidus, and Liquidus Temperatures

\begin{tabular}{|c|c|c|c|c|c|c|c|c|c|c|c|c|c|}
\hline \multirow[b]{2}{*}{ Alloy } & \multicolumn{3}{|c|}{$\gamma^{\prime}$ Solvus $\left({ }^{\circ} \mathrm{C}\right)$} & \multicolumn{3}{|c|}{ Solidus $\left({ }^{\circ} \mathrm{C}\right)$} & \multicolumn{3}{|c|}{ Liquidus $\left({ }^{\circ} \mathrm{C}\right)$} & \multicolumn{4}{|c|}{ Heat Treatment Window $\left({ }^{\circ} \mathrm{C}\right)$} \\
\hline & DSC & TCNi8 & TTNi8 & DSC & TCNi8 & TTNi8 & DSC & TCNi8 & TTNi8 & DSC & TCNi8 & TTNi8 & TC/TTNi8 \\
\hline SX1 & 1209 & 1273 & 1214 & 1333 & 1334 & 1321 & 1365 & 1369 & 1360 & 124 & 61 & 107 & 120 \\
\hline SX2 & 1200 & 1303 & 1222 & 1322 & 1286 & 1274 & 1358 & 1362 & 1353 & 122 & -17 & 52 & 64 \\
\hline SX3 & 1164 & 1257 & 1153 & 1324 & 1305 & 1293 & 1357 & 1347 & 1352 & 160 & 48 & 140 & 152 \\
\hline SX4 & 1211 & 1231 & 1188 & 1311 & 1301 & 1308 & 1345 & 1346 & 1346 & 100 & 70 & 120 & 113 \\
\hline SX5 & 1185 & 1221 & 1207 & 1331 & 1330 & 1303 & 1364 & 1372 & 1356 & 146 & 109 & 96 & 123 \\
\hline SX6 & 1195 & 1259 & 1179 & 1330 & 1328 & 1317 & 1362 & 1371 & 1361 & 135 & 69 & 138 & 149 \\
\hline
\end{tabular}

Heat treatment windows are calculated using values from DSC, TCNi8, TTNi8, and a combination of the two databases, taking the $\gamma^{\prime}$ solvus from TTNi8 and the solidus from TCNi8. 


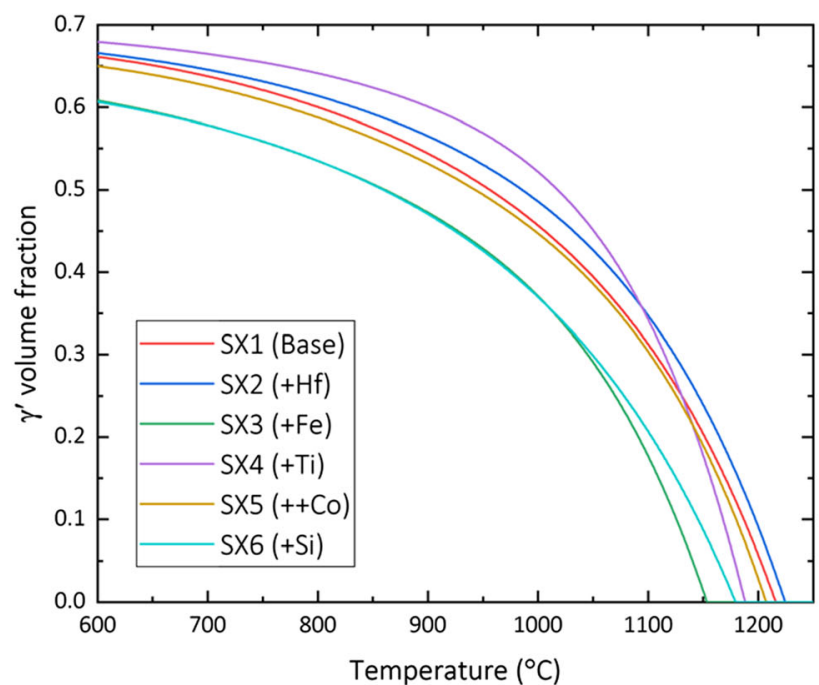

(a)

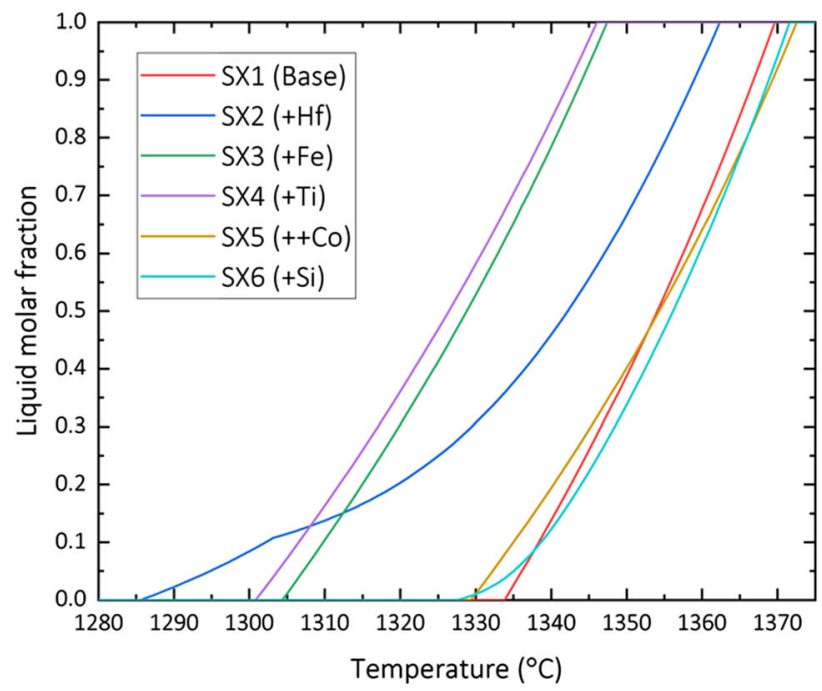

(c)

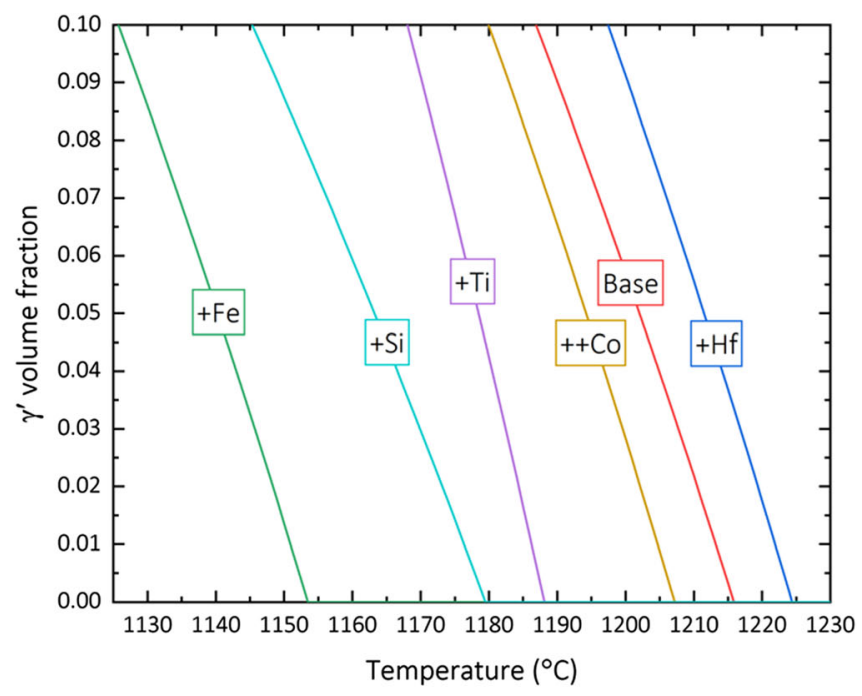

(b)

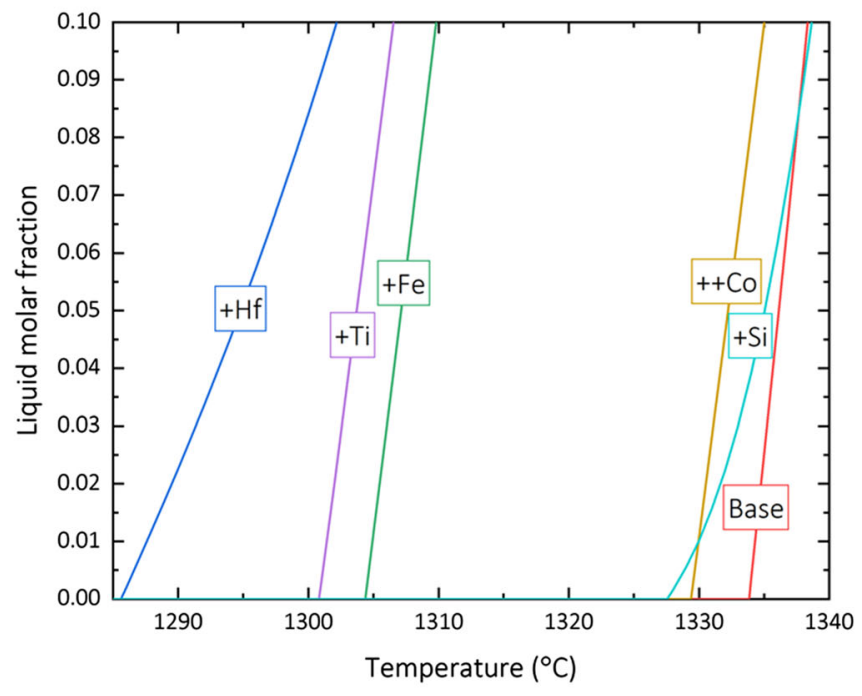

(d)

Fig. 6-Thermo-Calc predictions for the influence of temperature on $(a) \gamma^{\prime}$ volume fraction using the TTNi8 database and (c) liquid molar fraction using the TCNi8 database. The images in $(b)$ and $(d)$ present enlarged views of fractions below 10 pct.

solidus and a higher $\gamma^{\prime}$ volume fraction up to around $1000{ }^{\circ} \mathrm{C}$; however, this value falls rapidly at higher temperatures and results in an incorrect, lower solvus prediction compared with SX1.

The third chemical modification expected to restrict the HTW is the additional 1.05 at. pct Si in SX6. An early study by Miner ${ }^{[27]}$ showed that Si has a similar effect to Ti by lowering the solidus and liquidus and raising the solvus. This finding was confirmed by several later studies. ${ }^{[5,28,29]}$ While the solidus does decrease for SX6, the solvus is also reduced, which can be related to the lower measured Al content in this alloy. These findings are in agreement with Thermo-Calc predictions in Figure 6.

A substantial widening of the HTW is obtained by increasing the Co content from 4.9 to 10.3 at. pct in SX5. The effects of Co in superalloys were studied at length during the 1980s following critical supply shortages and revealed a complex influence of Co on alloy microstructure and properties. ${ }^{[30]}$ For example, the addition of 5.1 at. pet Co to a Co-free variation of alloy René N6 significantly raised both the solvus and the solidus, but maintained the same HTW.${ }^{[19]}$ Further additions up to 12.7 at. pct and 20.4 at. pct Co slightly lowered the solidus, but strongly reduced the solvus, resulting in a wider HTW. Similar results were obtained for Udimet 700 containing between 0 and 16 at. pct Co; however, the solvus showed a continuous decrease with increasing Co content. ${ }^{[31-33]}$ These same trends were found for alloys Mar-M247 and NASAIR 100 when increasing the Co level from 0 to 10 at. pct $^{[24,34]}$ and for a set of model $\mathrm{Ni}-\mathrm{Cr}-\mathrm{Co}-\mathrm{Al}-\mathrm{Ti}$ alloys containing between 0 and 57 at. pct Co. ${ }^{[35]}$ Thermo-Calc predictions are in line with these literature results and with the DSC data for SX5. 


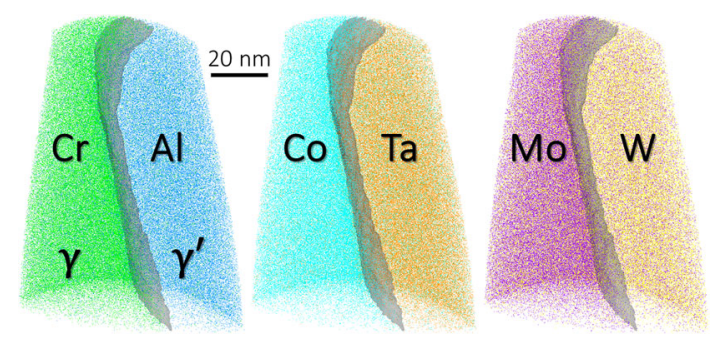

Fig. 7-3D reconstruction of an APT dataset of around 21 million ions for the base alloy SX1. For clarity, only a fraction of the $\mathrm{Cr} / \mathrm{Al}$, $\mathrm{Co} / \mathrm{Ta}$, and $\mathrm{Mo} / \mathrm{W}$ atoms are shown and $\mathrm{Ni}$ atoms are omitted altogether. The $\gamma / \gamma^{\prime}$ interface is shown in gray at an iso-concentration of 20 at. pet $\mathrm{Cr}$.

An even stronger effect of depressing the solvus is observed for SX3 after 6.5 at. pct Ni is substituted with $\mathrm{Fe}$. As the solidus is only slightly lowered, the overall HTW expands by almost $40{ }^{\circ} \mathrm{C}$. In commercial nickeland nickel-iron-based superalloys, $\mathrm{Fe}$ is either (1) completely avoided, as it promotes the precipitation of deleterious TCP phases and it lowers high-temperature strength, or (2) it is added in significantly higher quantities in low-cost, high-toughness materials for low-temperature applications. The only commercial composition similar to SX3 is the wrought alloy Haynes 214 , which contains 3 at. pet $\mathrm{Fe}$ and which has been designed for components operating in carburizing and/ or oxidizing environments. ${ }^{[36]}$ Hence, DSC data for comparable materials with around 5 at. pct $\mathrm{Fe}$ are lacking. Nonetheless, Thermo-Calc correctly reproduces the strong decrease in solvus, although it overestimates the lower solidus in Figure 6.

\section{APT Analysis of Alloy Microchemistry}

Figure 7 illustrates an exemplary 3D APT dataset collected for the base alloy SX1. The $\gamma$ matrix and a $\gamma^{\prime}$ precipitate are identified unambiguously as a result of the preferential partitioning of $\mathrm{Cr}, \mathrm{Co}$, and $\mathrm{Mo}$ to $\gamma$ and of Al and Ta to $\gamma^{\prime}$. To highlight the $\gamma / \gamma^{\prime}$ interface, an iso-concentration surface was generated at 20 at. pct $\mathrm{Cr}$. This cut-off value is used consistently for all six alloys.

\section{Phase compositions and element partitioning}

Phase compositions were estimated by generating cylindrical regions of interest at distances of at least 5 $\mathrm{nm}$ from the $\gamma / \gamma^{\prime}$ interfaces. Results are shown in Table IV, where they are compared with Thermo-Calc predictions for equilibrium conditions at $845^{\circ} \mathrm{C}$. Using this data, partitioning coefficients are calculated and are presented as $\log \left(K_{i}^{\gamma^{\prime} / \gamma}\right)$ in Table $\mathrm{V}$ and in Figure 8.

CALPHAD predictions and experimental results show a reasonable level of agreement. Some general trends emerge when considering the values of $K_{i}^{\gamma^{\prime} / \gamma}$ for each element $i$ in Table V. Thermo-Calc results consistently underestimate $K_{\mathrm{Ni}}^{\gamma^{\prime} / \gamma}, K_{\mathrm{Mo}}^{\gamma^{\prime} / \gamma}, K_{\mathrm{W}}^{\gamma^{\prime} / \gamma}$, and $K_{\mathrm{Al}}^{\gamma^{\prime} / \gamma}$, while overestimating $K_{\mathrm{Cr}}^{\gamma^{\prime} / \gamma}$. These differences could be related to phases not having attained their equilibrium compositions after heat treatment ${ }^{[37-39]}$ and/or to changes in chemistry during the final cooling after secondary aging at $845{ }^{\circ} \mathrm{C}$. However, considering the discrepancies observed between Thermo-Calc phase diagrams and experimental DSC results and the general lack of data for this region of the alloy design space, it is not surprising that phase compositions differ. The underestimated preferential partitioning of $\mathrm{Ni}$ and $\mathrm{Al}$ to the $\gamma^{\prime}$ phase also explains why Thermo-Calc estimates of the $\gamma^{\prime}$ volume fraction in Table II are lower than those based on SEM micrographs. Whether TCNi8 or TTNi8 will provide more accurate estimates depends on both the particular alloy and the element considered. Overall, TTNi8 values are closer to experimental results, in line with the more accurate predictions for $\gamma^{\prime}$ volume fractions and solvus temperatures.

\section{Lattice misfit effects on $\gamma / \gamma^{\prime}$ interface width}

Elemental partitioning profiles across $\gamma / \gamma^{\prime}$ interfaces set at iso-concentrations of 20 at. pct $\mathrm{Cr}$ are investigated by means of proximity histogram (proxigram) analyses. Proxigrams are computed $10 \mathrm{~nm}$ either side of the interface using a bin size of $0.1 \mathrm{~nm}$. Error bars represent one standard deviation calculated as $\sigma=$ $\sqrt{\left(C_{i}\left(1-C_{i}\right)\right) / N}$, where $C_{i}$ is the atomic fraction of element $i$ and $N$ is the total number of atoms in the bin.

The results in Figure 9 reveal diffuse, non-uniform interfaces between the plateau concentrations of $\gamma$ and $\gamma^{\prime}$. Interfacial widths, $\Delta_{i}$, for the profile of each element $i$ were calculated following the method proposed by Zhou et al. ${ }^{[40]}$ First, plateau concentration values were obtained using least-squares averaging. Second, non-linear curve fitting to hyperbolic tangent functions was performed using an Orthogonal Distance Regression algorithm. Adjusted $\mathrm{R}^{2}$ values were close to unity for all cases. Third, $\Delta_{i}$ was calculated by assuming that each interface begins 10 pct above the minimum and ends at 90 pct of the maximum plateau values.

As shown in Table VI, the magnitude of $\Delta_{i}$ correlates with the Vegard coefficients $\Gamma_{i}^{\gamma}$ and $\Gamma_{i}^{\gamma^{\prime}}$. These indicate how the presence of element $i$ will influence phase lattice constants and the misfit between $\gamma$ and $\gamma^{\prime}$, and are effectively measures of the size difference between solute $i$ and solvent $\mathrm{Ni}$ atoms. ${ }^{[41]} \mathrm{Mo}, \mathrm{Ti}$, and Ta all exhibit high interfacial widths, in agreement with recent APT reports on wrought disc superalloys. ${ }^{[38,39]}$ An exception is observed for $\mathrm{Cr}$, which reaches its plateau value in $\gamma$ more sluggishly than expected based on its relatively low Vegard coefficients. This discrepancy has recently been related to field evaporation artifacts caused by moving through the interface. ${ }^{[39]}$ Similar interfacial profiles of $\mathrm{Cr}$ were observed by Booth-Morrison et al. ${ }^{[42-44]}$ in model Ni-Cr-Al-Ta alloys, but were not discussed by the authors.

Using the phase compositions in Table IV and Vegard coefficients reported in the literature, ${ }^{[45,46]}$ it is possible to estimate the effects of composition on the lattice constants $a_{\gamma}$ and $a_{\gamma^{\prime}}$ at room temperature as follows: 


$$
a_{\gamma}=a_{0}^{\gamma}+\sum_{i} \Gamma_{i}^{\gamma} C_{i}^{\gamma} ; \quad a_{\gamma^{\prime}}=a_{0}^{\gamma^{\prime}}+\sum_{i} \Gamma_{i}^{\gamma^{\prime}} C_{i}^{\gamma^{\prime}}
$$

where $a_{0}^{j}$ is the lattice constant of pure $\mathrm{Ni}$ or pure $\mathrm{Ni}_{3} \mathrm{Al}$, and $\Gamma_{i}^{j}$ and $C_{i}^{j}$ are the Vegard coefficient and the atomic fraction of chemical element $i$ in phase $j$. Following Caron, ${ }^{[41]} a_{0}^{\gamma}$ and $a_{0}^{\gamma^{\prime}}$ are taken as $3.524 \AA$ and $3.57 \AA$, respectively. The room temperature (RT) values shown in Table VII are then scaled to the secondary aging temperature of $845^{\circ} \mathrm{C}$ using empirical relations reported by Kamara et al. ${ }^{[47]}$ Finally, the lattice misfit, $\delta$, can be obtained as $\delta=2\left(a_{\gamma^{\prime}}-a_{\gamma}\right) /\left(a_{\gamma^{\prime}}+a_{\gamma}\right)$. Comparison is also made in Table VII with misfit values estimated using the same general approach, but with phase composition data predicted by $\mathrm{TCNi} 8$ at $845{ }^{\circ} \mathrm{C}$. Furthermore, another CALPHAD-based method is considered, in which lattice constants are calculated from the molar volumes predicted by TCNi8. As both $\gamma$ and $\gamma^{\prime}$ contain 4 atoms in each unit cell, lattice constants $a_{j}$ can be obtained as $a_{j}=\left(4 V_{\mathrm{m}}^{j} / N_{\mathrm{A}}\right)^{1 / 3}$, where $V_{\mathrm{m}}^{j}$ is the calculated molar volume of phase $j$ and $N_{\mathrm{A}}$ is the Avogadro constant.

Misfit results in column 'APT' are in good qualitative agreement with the observed precipitate shapes in Figure 2. It has been shown that $\gamma^{\prime}$ morphology changes from spheroidal to globular and eventually to cuboidal as the absolute value of misfit, $|\delta|$, increases. ${ }^{[48,49]}$ For alloys exhibiting irregular, rounded shapes-SX1 and SX4, relatively low misfit values are predicted, whereas higher ones are obtained for alloys with regular, cuboidal structures-SX2, SX3, and SX6. The only exception from this trend is SX5, which exhibits blocky precipitates with sharp edges despite its low predicted misfit. Reasonable agreement is also found when considering the values in the 'TCNi8' column based on Thermo-Calc phase compositions. In agreement with a recent APT study on model Ni-Cr-Al-Ti-Mo alloys, ${ }^{[50]}$ the approach of estimating lattice constants using molar volumes from TCNi8 is found to be inaccurate. Finally, it should be noted that for IGT alloys a low misfit magnitude is desirable, as this will limit the driving force for precipitate coarsening during long-term service. ${ }^{[51]}$ As such, chemical additions which strongly influence lattice misfit, including $\mathrm{Mo}, \mathrm{Ti}$, and $\mathrm{Ta}$, must be carefully balanced.

\section{DISCUSSION: CHEMICAL ELEMENT INTERACTIONS IN IGT ALLOYS}

Results from electron microscopy, DSC, and APT analyses have revealed complex interactions between different chemical additions in the six investigated alloys. Understanding how these interactions in turn influence microstructure and material properties is crucial for increasing the accuracy and reliability of alloy design tools. In the following, these aspects are discussed separately for each chemical variation, with some overarching trends also emerging.

\section{A. On the Effects of $H f$ in $S X 2$}

Hf became a key addition to superalloys after it was found to significantly increase creep ductility and the time to rupture by influencing grain boundary microstructure in both conventionally cast and directionally solidified components. ${ }^{[2,52,53]}$ Further advantages of adding $\mathrm{Hf}$ include improved castability, as the probability of hot tearing is reduced, ${ }^{[25,26]}$ and increased resistance to sulfidation and to isothermal and cyclic oxidation, as $\mathrm{Hf}$ acts as a getter of $\mathrm{S}$ and improves the adherence of oxide scales and of thermal barrier coatings. ${ }^{[54-56]} \mathrm{A}$ main downside of $\mathrm{Hf}$ is its strong reduction of the available HTW, although for SX2 this has been shown to remain large enough to enable full homogenization.

The results in Table $\mathrm{V}$ and Figure 8(a) reveal a further benefit of $\mathrm{Hf}$ in $\mathrm{SX} 2$, as the partitioning coefficients of $\mathrm{W}$ and Mo are reduced. A higher content of slow-diffusing $\mathrm{W}$ and Mo in the $\gamma$ matrix implies a reduced rate of diffusion-controlled dislocation movement, which constitutes a key damage accumulation mechanism during service for IGT alloys. ${ }^{[11]}$ The effect of $\mathrm{Hf}$ on partitioning behaviors can be understood by considering the preference of different elements for either $\mathrm{Ni} \alpha$-sublattice sites or $\mathrm{Al} \beta$-sublattice sites within the $\gamma^{\prime}$ phase. Results of previous APT studies on nickel-based superalloys are compiled in Table VIII, while Thermo-Calc predictions for equilibrium conditions at $845^{\circ} \mathrm{C}$ are shown in Table IX. It emerges that $\mathrm{Hf}$, Mo, and $\mathrm{W}$ all prefer Al sublattice sites, suggesting that $\mathrm{W}$ and Mo are displaced by Hf into the $\gamma$ matrix in SX2.

From an alloy design perspective, it must be pointed out that the preferential partitioning of Hf towards $\gamma^{\prime}$ in SX2, which directly influences its efficiency at displacing $\mathrm{W}$ and Mo, has been shown to vary with alloy chemistry. Recent studies ${ }^{[38,57]}$ proposed that $K_{\mathrm{Hf}}^{\gamma^{\prime} / \gamma}$ depends on the ratio of $\mathrm{Cr}$ to $\mathrm{Co}$ additions. At a low $\mathrm{Cr} / \mathrm{Co}$ ratio, it is anticipated that Co will stabilize the $\gamma^{\prime}$ phase for $\mathrm{Hf}$, whereas at a high $\mathrm{Cr} / \mathrm{Co}$ ratio, $\mathrm{Cr}$ will increase the solubility of $\mathrm{Hf}$ in the $\gamma$ matrix and will reverse partitioning. ${ }^{[58,59]}$ However, the data compiled from literature in Table $\mathrm{X}$ suggest that $\mathrm{Hf}$ partitioning is not as simple as previously suggested. Alloy SX2, with double the $\mathrm{Cr} / \mathrm{Co}$ ratio compared with ME-9 and ME-15, exhibits a $K_{\mathrm{Hf}}^{\gamma^{\prime} / \gamma}$ value two orders of magnitude higher. Furthermore, alloys CMSX-4 and RR1000, with similar $\mathrm{Cr} / \mathrm{Co}$ ratios to ME-9 and ME-15, still exhibit a clear partitioning of $\mathrm{Hf}$ towards $\gamma^{\prime}$. It is therefore suggested that the dependence of $K_{\mathrm{Hf}}^{\gamma^{\prime} / \gamma}$ on the $\mathrm{Cr} / \mathrm{Co}$ ratio only holds true for low $\mathrm{Hf}$ additions on the order of 0.05 at. pct.

\section{B. On the Effects of Ti in SX4}

APT observations and first-principle calculations of substitutional formation energies have revealed a strong effect of Ta additions for displacing $\mathrm{W}$ into the $\gamma$ matrix and reversing its partitioning. ${ }^{[60-62]}$ This has been related to the high affinity of Ta for the $\gamma^{\prime}$ phase and to the 


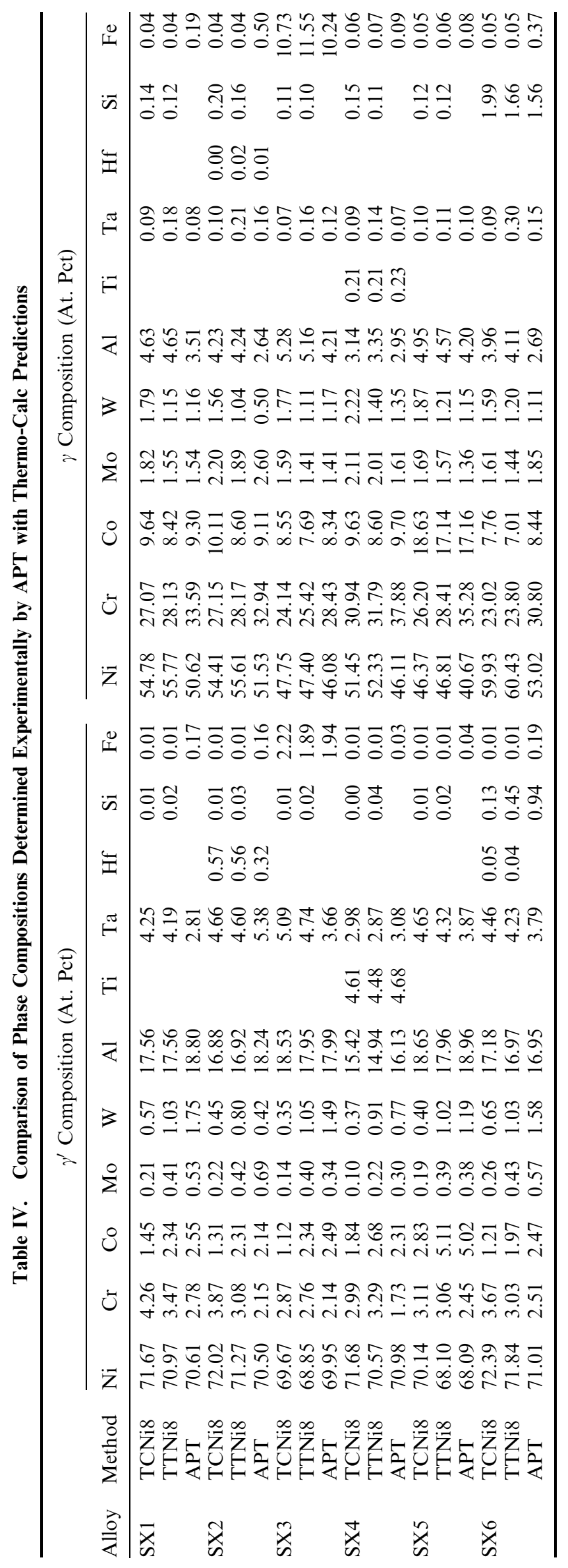


Table V. Comparison of Phase Partitioning Coefficients Determined Using the Data in Table IV

\begin{tabular}{|c|c|c|c|c|c|c|c|c|c|c|c|c|}
\hline \multirow[b]{2}{*}{ Alloy } & \multirow[b]{2}{*}{ Method } & \multicolumn{11}{|c|}{ Partitioning Coefficient $\log \left(K_{i}^{\gamma^{\prime} / \gamma}\right)$} \\
\hline & & $\mathrm{Ni}$ & $\mathrm{Cr}$ & $\mathrm{Co}$ & Mo & W & $\mathrm{Al}$ & $\mathrm{Ti}$ & $\mathrm{Ta}$ & $\mathrm{Hf}$ & $\mathrm{Si}$ & $\mathrm{Fe}$ \\
\hline \multirow[t]{3}{*}{ SX1 } & TCNi8 & 0.12 & -0.80 & -0.82 & -0.93 & -0.49 & 0.58 & & 1.70 & & & \\
\hline & TTNi8 & 0.10 & -0.91 & -0.56 & -0.57 & -0.05 & 0.58 & & 1.37 & & & \\
\hline & APT & 0.14 & -1.08 & -0.56 & -0.47 & 0.18 & 0.73 & & 1.55 & & & \\
\hline \multirow[t]{3}{*}{$\mathrm{SX} 2$} & TCNi8 & 0.12 & -0.85 & -0.89 & -1.01 & -0.54 & 0.60 & & 1.66 & 2.22 & & \\
\hline & TTNi8 & 0.11 & -0.96 & -0.57 & -0.66 & -0.11 & 0.60 & & 1.33 & 1.40 & & \\
\hline & $\mathrm{APT}$ & 0.14 & -1.19 & -0.63 & -0.57 & -0.08 & 0.84 & & 1.52 & 1.72 & & \\
\hline \multirow[t]{3}{*}{$\mathrm{SX} 3$} & TCNi8 & 0.16 & -0.93 & -0.88 & -1.05 & -0.71 & 0.54 & & 1.88 & & & -0.68 \\
\hline & TTNi8 & 0.16 & -0.96 & -0.52 & -0.55 & -0.02 & 0.54 & & 1.46 & & & -0.79 \\
\hline & APT & 0.18 & -1.12 & -0.52 & -0.62 & 0.10 & 0.63 & & 1.49 & & & -0.72 \\
\hline \multirow[t]{3}{*}{ SX4 } & TCNi8 & 0.14 & -1.01 & -0.72 & -1.31 & -0.78 & 0.69 & 1.35 & 1.51 & & & \\
\hline & TTNi8 & 0.13 & -0.99 & -0.51 & -0.96 & -0.19 & 0.65 & 1.33 & 1.31 & & & \\
\hline & $\mathrm{APT}$ & 0.19 & -1.34 & -0.62 & -0.73 & -0.25 & 0.74 & 1.30 & 1.64 & & & \\
\hline \multirow[t]{3}{*}{ SX5 } & TCNi8 & 0.18 & -0.93 & -0.82 & -0.95 & -0.67 & 0.58 & & 1.67 & & & \\
\hline & TTNi8 & 0.16 & -0.97 & -0.53 & -0.60 & -0.08 & 0.59 & & 1.61 & & & \\
\hline & $\mathrm{APT}$ & 0.22 & -1.16 & -0.53 & -0.55 & 0.01 & 0.65 & & 1.60 & & & \\
\hline \multirow[t]{3}{*}{ SX6 } & TCNi8 & 0.08 & -0.80 & -0.81 & -0.80 & -0.39 & 0.64 & & 1.68 & 2.33 & -1.19 & \\
\hline & TTNi8 & 0.08 & -0.90 & -0.55 & -0.52 & -0.07 & 0.62 & & 1.15 & 1.31 & -0.57 & \\
\hline & APT & 0.13 & -1.09 & -0.53 & -0.51 & 0.15 & 0.80 & & 1.39 & & -0.22 & \\
\hline
\end{tabular}

repulsive interatomic interactions of $\mathrm{Ta}-\mathrm{W}$ dimers. More recently, a similar, albeit weaker effect was found for $\mathrm{Ti}^{[63,64]}$ in agreement with the site preferences in Tables VIII and IX. Despite its downsides of lowering oxidation resistance ${ }^{[65-67]}$ and the available HTW, ${ }^{[19,41]}$ Ti has the advantage of significantly lower density and cost compared with $\mathrm{Ta}$, and it has been given preference in recent design studies of superalloys with optimized solid solution strengthening. $\left.{ }^{63}, 64\right]$

Results from image analysis of SEM micrographs indicate a significant increase in the $\gamma^{\prime}$ volume fraction of $\mathrm{SX} 4$, in agreement with the raised solvus temperature and with Thermo-Calc predictions. Thus, the reduced partitioning coefficients of $\mathrm{W}$ and Mo in SX4 can be related to both a higher precipitate volume fraction and to the effects of $\mathrm{Ti}$ and $\mathrm{Ta}$ atoms occupying Al sublattice sites. ${ }^{[64]}$ The value of $K_{\mathrm{Cr}}^{\gamma^{\prime} / \gamma}$ also decreases, suggesting that $\mathrm{Cr}$ may preferentially occupy $\beta$-sites in the trial IGT alloys considered here. However, it should be noted that the sublattice preference of $\mathrm{Cr}$ can vary strongly with composition and heat treatment, ${ }^{[4]}$ as summarized in Table VIII.

\section{On the Effects of $\mathrm{Fe}$ in $\mathrm{SX3}$ and Co in SX5}

In agreement with the reduced solvus temperatures and with Thermo-Calc predictions, the $\gamma^{\prime}$ volume fractions of alloys SX3 and SX5 are lower than for SX1. Accordingly, it might be expected that the concentrations of refractory elements in the $\gamma$ matrix will decrease with added $\mathrm{Fe}$ and Co. Furthermore, Table VIII shows only a weak preference of $\mathrm{Fe}$ for $\mathrm{Al}$ sublattice sites in a model Ni-Al-B-Fe alloy, while Co is found to either occupy $\mathrm{Ni}$ sites preferentially or both $\mathrm{Al}$ and $\mathrm{Ni}$ sites in an equal measure. Nonetheless, a noticeable reduction of $K_{\mathrm{Mo}}^{\gamma^{\prime} / \gamma}$ and $K_{\mathrm{W}}^{\gamma^{\prime} / \gamma}$ is observed for both SX3 and SX5, thus warranting a careful analysis.

A review of relevant literature reports reveals a complex and highly composition-dependent influence of Co on the partitioning coefficients of other elements. For Udimet 700 alloys with Co contents between 0 and 16 at. pct, Jarrett and Tien ${ }^{[31]}$ found using STEM-EDX that $K_{\mathrm{Cr}}^{\gamma^{\prime} / \gamma}$ decreases and $K_{\mathrm{Ni}}^{\gamma^{\prime} / \gamma}$ increases with added Co, in agreement with the present work, while the partitioning behaviors of $\mathrm{Co}, \mathrm{Al}$, Ti, and Mo were not affected. Surprisingly, $\operatorname{Harf}^{[33]}$ found no significant changes in partitioning for the same set of Udimet 700 compositions, when these were prepared by a powder metallurgical route. In an extensive study on the influence of Co, $\mathrm{Ta}$, and $\mathrm{W}$ on the microstructure of single-crystal superalloys similar to NASAIR 100, Nathal and Ebert $^{[24]}$ measured phase chemistries after electrolytic phase extractions and only found significant changes for $\mathrm{Ni}$, which partitioned more strongly to $\gamma^{\prime}$ as the Co content was increased from 0 to 10 at. pct. The same results were reported by Zhi'An et al., ${ }^{[68]}$ who examined a set of Udimet 500 alloys with 0 to 23.5 at. pet Co. A recent APT study on model Ni-Cr-Co-Al-Ti alloys containing between 0 and 57 at. pct $\mathrm{Co}^{[35]}$ found that, between 0 and 19 at. pct $\mathrm{Co}, K_{\mathrm{Cr}}^{\gamma^{\prime} / \gamma}$ decreases and $K_{\mathrm{Ni}}^{\gamma^{\prime}} / \gamma$ strongly rises, in accordance with results for SX1 and SX5, however, also contrarily that $K_{\mathrm{Al}}^{\gamma^{\prime} / \gamma}$ increases. The best agreement of results for SX 5 is found with a report by Nathal et al. ${ }^{[34]}$ on conventionally cast Mar-M247 containing between 0 and 10 at. pct Co. These authors found that $K_{\mathrm{Ni}}^{\gamma^{\prime} / \gamma}$ strongly increases and that $K_{\mathrm{Cr}}^{\gamma^{\prime} / \gamma}, K_{\mathrm{Al}}^{\gamma^{\prime} / \gamma}$, and $K_{\mathrm{W}}^{\gamma^{\prime} / \gamma}$ gradually decrease as more Co is added. All in all, this brief review demonstrates that the impact of $\mathrm{Co}$ in superalloys has not yet been fully understood and that 


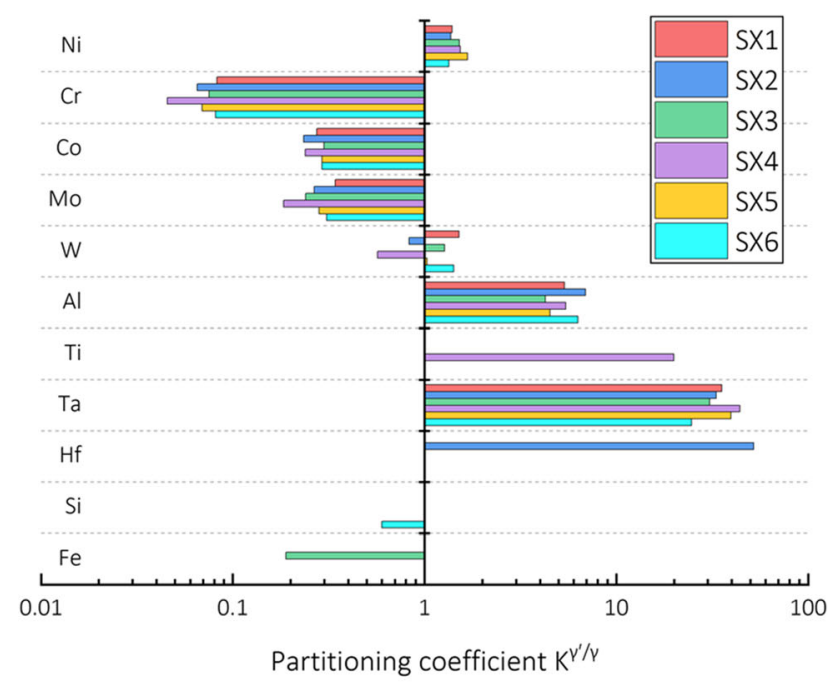

(a)

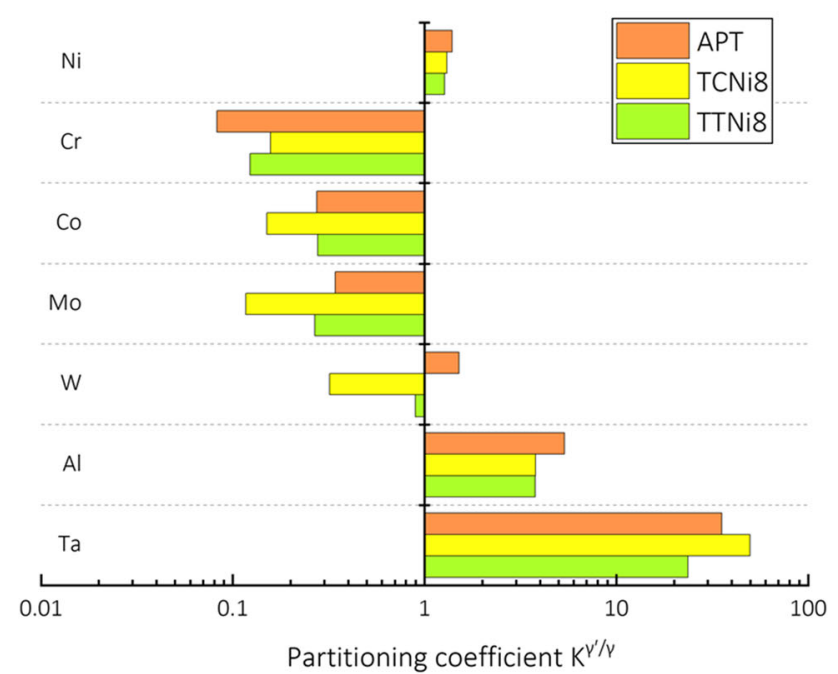

(b)

Fig. 8-Phase partitioning coefficients determined $(a)$ for the six trial alloys using APT results and $(b)$ for the base alloy SX1 using APT and Thermo-Calc results.

its effects are highly dependent on composition and even heat treatments. ${ }^{[32]}$

The scarcity of data on alloys containing relatively low levels of $\mathrm{Fe}$ makes it difficult to assess the result for SX3. The seminal review by Ochiai et al ${ }^{[69]}$ on site preferences in $\mathrm{Ni}_{3} \mathrm{Al}$ showed a mixed behavior for $\mathrm{Fe}$ and a roughly equal preference for $\mathrm{Ni}$ and $\mathrm{Al}$ sublattice sites. An earlier study by Nicholls and Rawlings ${ }^{[70]}$ on $\mathrm{Ni}_{3} \mathrm{Al}(\mathrm{Fe})$ alloys found the site preference of $\mathrm{Fe}$ changes from $\mathrm{Al} \beta$-sublattice sites at 2.5 at. pct Fe to mixed at 9.3 at. pct. This is in agreement with the work of Miller and Horton, ${ }^{[71]}$ who found a weak $\beta$ preference in a $\mathrm{Ni}-\mathrm{Al}-\mathrm{B}-\mathrm{Fe}$ alloy with 6 at. pet Fe. Thus, it can be surmised that most of the 2 at. pct Fe measured for the $\gamma^{\prime}$ phase of SX3 will occupy Al sublattice sites. This can explain why the partitioning coefficients of Mo, W, Al, and Ta all decrease. From an alloy design perspective, potential improvements in oxidation resistance associated with $\mathrm{Fe}$ must be carefully considered against the significant reduction in $\gamma^{\prime}$ volume fraction, which will negatively impact high-temperature mechanical properties.

\section{On the Effects of Si in SX6}

A similar situation to $\mathrm{Fe}$ emerges for $\mathrm{Si}$ additions in superalloys. Previous research has shown that while $\mathrm{Si}$ improves hot corrosion and oxidation resistance, it can also negatively affect mechanical properties and promote the formation of deleterious TCP phases..$^{[5,27-29,72]}$ An optimal Si level of around 0.5 at. pct was reported for alloy STAL15SX, ${ }^{[5,72]}$ which possesses a similar chemical composition to the trial IGT alloys considered here.

Analogue to $\mathrm{Hf}$, the partitioning preference of $\mathrm{Si}$ towards $\gamma$ or $\gamma^{\prime}$ is influenced by the overall chemical composition. Based on results from several APT studies compiled in Table X, a good correlation is found between $K_{\mathrm{Si}}^{\gamma^{\prime} / \gamma}$ and the ratio of nominal $\mathrm{Cr} / \mathrm{Co}$ compositions. Therefore, the aforementioned considerations regarding the stabilizing effects of $\mathrm{Cr}$ and $\mathrm{Co}$ on $\gamma$ and $\gamma^{\prime}$, respectively, may explain the stronger partitioning of $\mathrm{Si}$ towards $\gamma$ for an increasing $\mathrm{Cr} / \mathrm{Co}$ ratio. It should be noted that Yeh et al. ${ }^{[29]}$ previously related this shift towards $\gamma$ to the presence of Ti; however, this hypothesis is not supported by the present work nor by APT results for STAL15SX. ${ }^{[73]}$ A comparison of partitioning coefficients for alloy CM247LC without $\mathrm{Si}$ and with additions of 0.53 and 1.06 at. pet suggested that $\mathrm{Si}$ shifts all $K^{\gamma^{\prime} / \gamma}$ values towards unity. ${ }^{[29]}$ This trend is also observed in SX6 for Ni, W, and Ta, but other results are inconclusive. Given the reduced nominal level of $\mathrm{Al}$ in this alloy, it is challenging to isolate the effects of $\mathrm{Si}$.

\section{E. On the Interfacial Enrichment of $W$ in $S X 2, S X 4$, and $S X 5$}

An interesting result observed in Figure 9 for alloys SX2, SX4, and SX5 is an enrichment of $\mathrm{W}$ at $\gamma / \gamma^{\prime}$ interfaces. No such effect could be observed for SX1, SX3, or SX6, suggesting that it is related to the reversed partitioning of $\mathrm{W}$ towards the $\gamma$ matrix. Extensive work on the partitioning behavior of $\mathrm{W}$ and the influence of $\mathrm{Ta}^{[60-62,74]}$ clearly showed that $\mathrm{W}$ segregation only occurs in alloys with a high enough Ta content to effectively displace $\mathrm{W}$ atoms from their preferred $\mathrm{Al}$ $\beta$-sublattice sites and into the $\gamma$ phase. Conversely, no W enrichment was observed in model ternary, quaternary, and quinary alloys with lower levels of $\mathrm{Ta}$ or in the Ta-depleted dendrite core regions of multi-component superalloys. ${ }^{[60-62,74]}$ Considering the literature reports compiled in Table XI, it appears the condition $K_{\mathrm{X}}^{\gamma^{\prime} / \gamma}<1$ is indeed a prerequisite for the enrichment of solute $\mathrm{X}$ at $\gamma / \gamma^{\prime}$ interfaces, but it does not guarantee this will indeed occur.

From an alloy design perspective, it is important to assess what gives rise to interfacial solute segregation and, more so, how this might impact high-temperature creep resistance. Early APT studies hypothesized that 


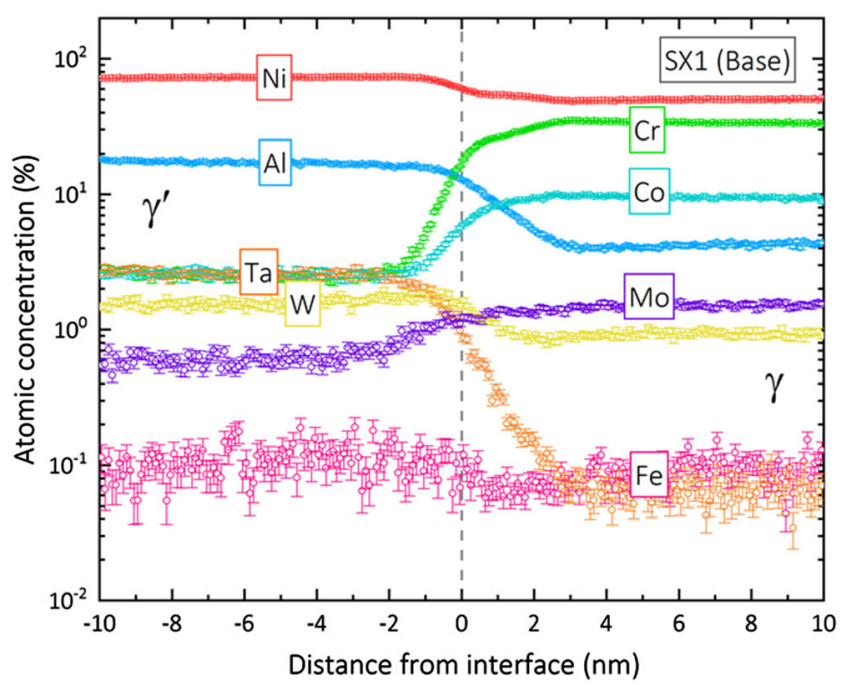

(a)

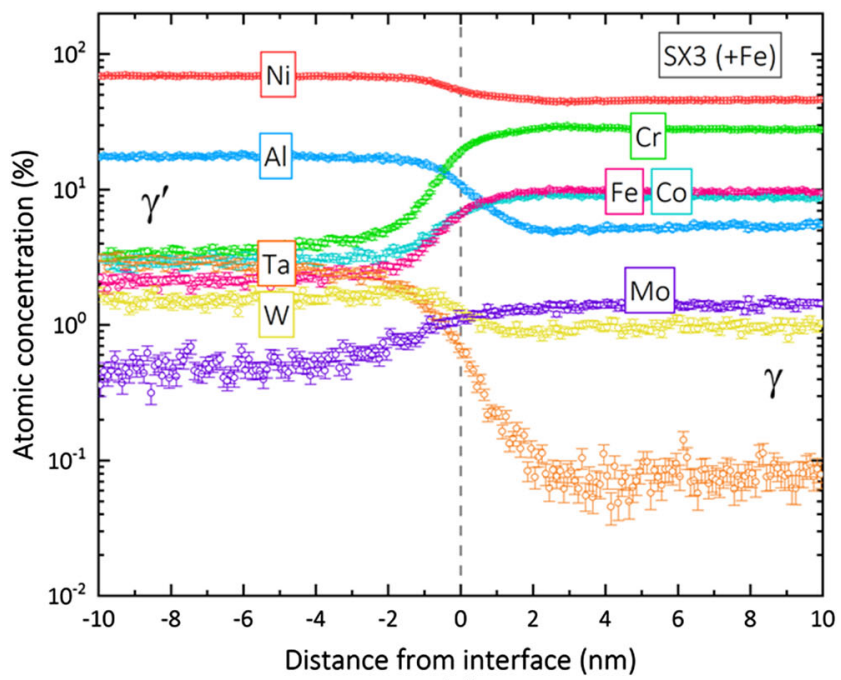

(c)

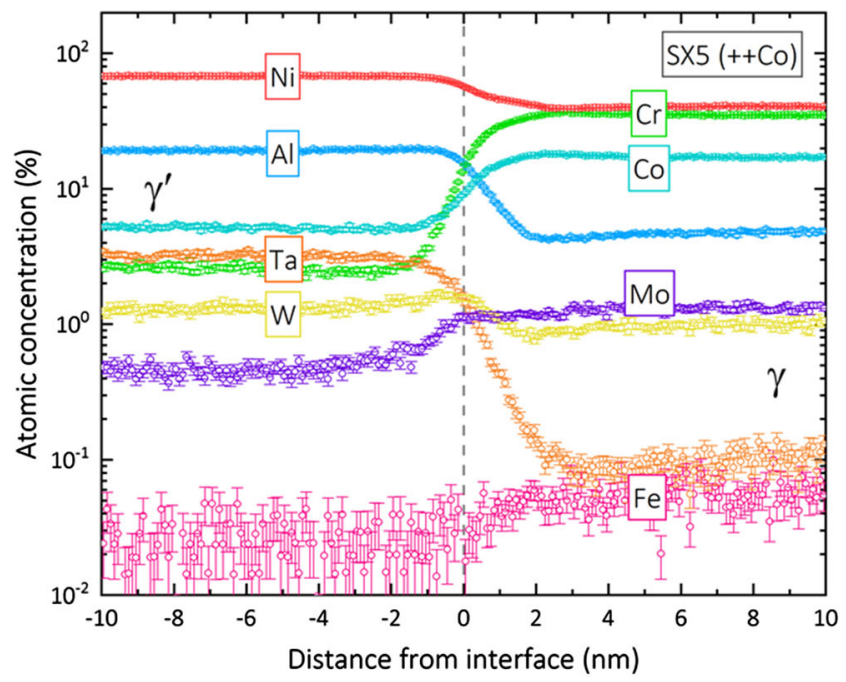

(e)

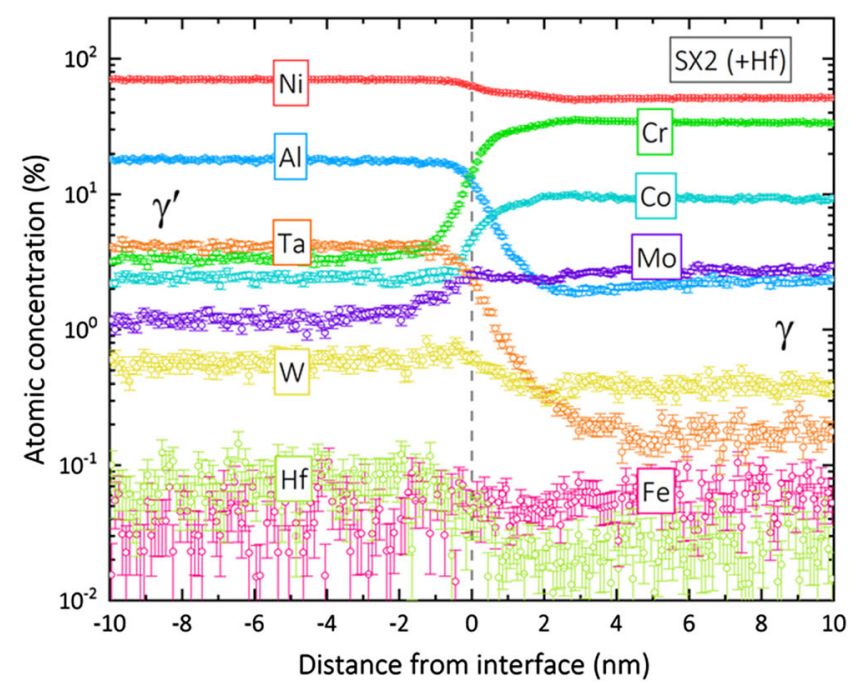

(b)

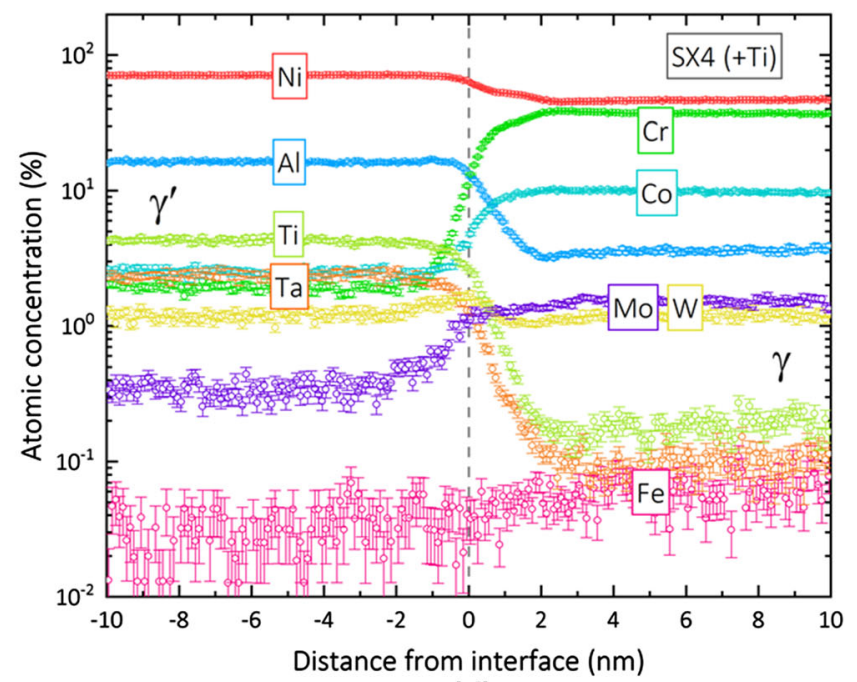

(d)

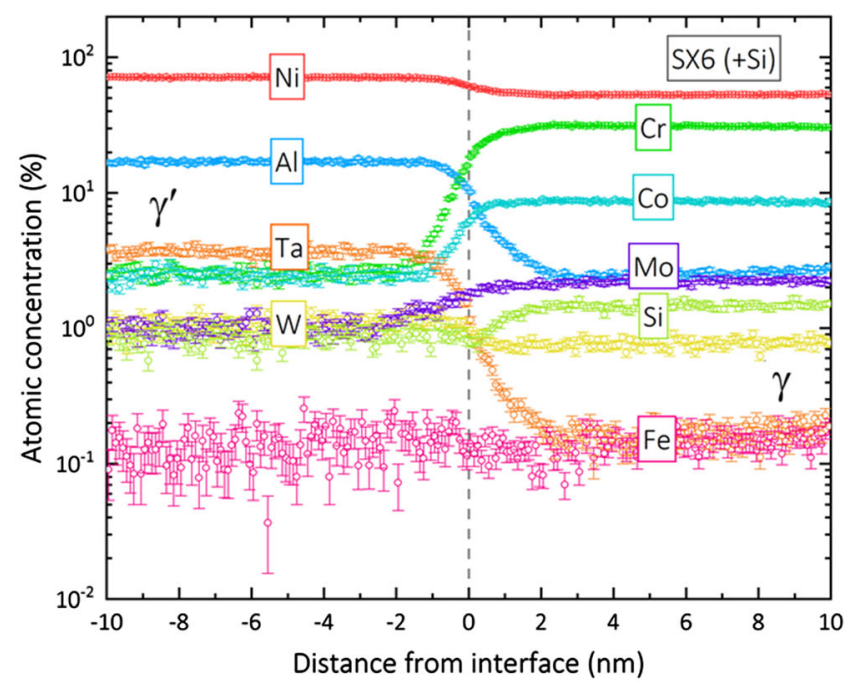

(f)

Fig. 9- (a) through $(f)$ Proxigrams across $\gamma / \gamma^{\prime}$ interfaces for the six trial alloys, set at iso-concentrations of 20 at. pct Cr. Negative distance values are into a $\gamma^{\prime}$ precipitate and positive ones are into the $\gamma$ matrix. Error bars represent $\pm \sigma$ confidence intervals; for some elements these overlap with the solid symbols and are not visible. 
Table VI. Widths of $\gamma / \gamma^{\prime}$ Interfaces from Fig. 9, Calculated Following Ref. [40]

\begin{tabular}{|c|c|c|c|c|c|c|c|c|c|c|c|}
\hline \multirow[b]{2}{*}{ Alloy } & \multicolumn{11}{|c|}{ Interfacial Width $\Delta_{i}(\mathrm{~nm})$} \\
\hline & $\mathrm{Ni}$ & $\mathrm{Cr}$ & $\mathrm{Co}$ & Mo & $\mathrm{W}$ & $\mathrm{Al}$ & $\mathrm{Ti}$ & $\mathrm{Ta}$ & $\mathrm{Hf}$ & $\mathrm{Si}$ & $\mathrm{Fe}$ \\
\hline SX1 & 0.90 & 3.50 & 2.46 & 4.90 & 0.71 & 3.99 & & 5.18 & & & \\
\hline $\mathrm{SX} 2$ & 0.71 & 2.82 & 1.87 & 3.39 & 0.48 & 2.58 & & 3.49 & 1.80 & & \\
\hline SX3 & 1.42 & 3.79 & 2.80 & 5.03 & 0.65 & 2.71 & & 8.48 & & & 3.33 \\
\hline SX4 & 0.91 & 2.45 & 1.63 & 3.98 & 0.04 & 1.35 & 3.49 & 3.41 & & & \\
\hline SX5 & 1.25 & 2.65 & 1.73 & 4.02 & 0.19 & 1.51 & & 4.55 & & & \\
\hline SX6 & 0.67 & 2.81 & 1.60 & 3.41 & 3.41 & 2.45 & & 2.97 & & 0.91 & \\
\hline$\overline{\Delta_{i}}(\mathrm{~nm})$ & 1.17 & 3.60 & 2.42 & 4.95 & 1.10 & 2.92 & 3.49 & 5.61 & 1.80 & 0.91 & 3.33 \\
\hline$\Gamma_{i}^{\gamma}(-)$ & - & 0.11 & 0.0196 & 0.478 & 0.444 & 0.179 & 0.422 & 0.7 & 1.03 & - & 0.15 \\
\hline$\Gamma_{i}^{\gamma^{\prime}}(-)$ & - & -0.004 & 0 & 0.208 & 0.194 & 0 & 0.258 & 0.5 & 0.78 & - & -0.004 \\
\hline
\end{tabular}

Average values, $\overline{\Delta_{i}}$, are compared to the unitless vegard coefficients $\Gamma_{i}^{\gamma}$ and $\Gamma_{i}^{\gamma^{\prime}}$ obtained from References 45 and 46 .

Table VII. Comparison of Lattice Misfit, $\delta$, Calculated (1) Using the Vegard Coefficients in Table VI and Phase Compositions from APT, (2) with the Same Approach as (1) but Using Phase Compositions from TCNi8, and (3) Based on Predicted Molar Volumes of the Phases from TCNi8

\begin{tabular}{|c|c|c|c|c|c|c|c|}
\hline \multirow[b]{2}{*}{ Alloy } & \multicolumn{2}{|c|}{$a_{\gamma}(\AA)$} & \multicolumn{2}{|c|}{$a_{\gamma^{\prime}}(\AA)$} & \multicolumn{3}{|c|}{ Lattice Misfit $\delta\left(\times 10^{-3}\right)$} \\
\hline & RT & $845^{\circ} \mathrm{C}$ & RT & $845^{\circ} \mathrm{C}$ & (1) APT & (2) TCNi8 & (3) $V_{\mathrm{m}}$ \\
\hline SX1 & 3.582 & 3.645 & 3.588 & 3.643 & -0.590 & 0.877 & -2.448 \\
\hline $\mathrm{SX} 2$ & 3.583 & 3.646 & 3.602 & 3.656 & 2.737 & 2.490 & -0.963 \\
\hline SX3 & 3.593 & 3.655 & 3.592 & 3.646 & -2.471 & -1.551 & -0.536 \\
\hline SX4 & 3.588 & 3.651 & 3.599 & 3.654 & 0.864 & 0.640 & -2.764 \\
\hline SX5 & 3.586 & 3.649 & 3.592 & 3.647 & -0.528 & 0.987 & -2.230 \\
\hline SX6 & 3.580 & 3.643 & 3.593 & 3.648 & 1.424 & 3.490 & -0.276 \\
\hline
\end{tabular}

Table VIII. Site Preferences of Elements Within the $\gamma^{\prime}$ Phase for Either Ni $\alpha$-Sublattice Sites or Al $\beta$-Sublattice Sites

\begin{tabular}{|c|c|c|c|c|c|c|c|c|c|c|c|c|}
\hline Study & Material & $\mathrm{Ni}$ & $\mathrm{Cr}$ & Co & Mo & $\mathrm{W}$ & $\mathrm{Al}$ & $\mathrm{Ti}$ & $\mathrm{Ta}$ & $\mathrm{Hf}$ & $\mathrm{Fe}$ & Other \\
\hline Blavette and Bostel ${ }^{[82]}$ & CMSX-2 & $\alpha$ & $\alpha$ & $\alpha$ & & $\beta$ & $\beta$ & $\beta *$ & $\beta$ & & & \\
\hline Blavette et al. ${ }^{[83]}$ & ONERA alloy & $\alpha$ & $\alpha$ & $\alpha$ & $\beta$ & & $\beta$ & $\beta *$ & & & & $\mathrm{Nb}: \beta$ \\
\hline Miller and Horton ${ }^{[71]}$ & $\mathrm{Ni}-\mathrm{Al}-\mathrm{B}-\mathrm{X}(\mathrm{X}=\mathrm{Co} / \mathrm{Hf} / \mathrm{Fe})$ & $\alpha$ & & $\alpha$ & & & $\beta$ & & & $\beta$ & $\beta *$ & \\
\hline Blavette et $a .^{[84]}$ & CMSX-2 and PWA1480 & $\alpha$ & $\alpha$ & $\alpha$ & & $\beta$ & $\beta$ & $\beta$ & $\beta$ & & & $\operatorname{Re}: \beta$ \\
\hline More and Miller ${ }^{[85]}$ & Udimet 720 & $\alpha$ & $\alpha$ & $\alpha$ & $\beta$ & $\beta$ & $\beta$ & $\beta$ & & & & \\
\hline Harada et al..$^{[86]}$ & TMS-63 & $\alpha$ & $\alpha$ & & $\beta$ & & $\beta$ & & $\beta$ & & & \\
\hline Duval et al. ${ }^{[87]}$ & MC2 & $\alpha$ & $\beta *$ & $=$ & $\beta$ & $\beta$ & $\beta$ & $\beta$ & $\beta$ & & & \\
\hline Miller et al. ${ }^{[88]}$ & PWA 1480 & $\alpha$ & $\alpha *$ & $\alpha$ & & $\beta$ & $\beta$ & $\beta$ & $\beta$ & & & \\
\hline Murakami et al. ${ }^{[89]}$ & CMSX-4 & $\alpha$ & $\alpha$ & $\alpha *$ & $\beta$ & $\beta$ & $\beta$ & $\beta *$ & $\beta$ & $\beta$ & & $\operatorname{Re}: \beta$ \\
\hline Jayaram and Miller $^{[90]}$ & Ni-Al-Ta-Mo & $\alpha$ & & & $=$ & & $\beta$ & $\beta$ & & & & \\
\hline Wanderka and Glatzel ${ }^{[75]}$ & CMSX-4 & $\alpha$ & $\alpha$ & $\alpha$ & & $=$ & $\beta$ & $\alpha$ & $\beta$ & & & \\
\hline Murakami et al. ${ }^{[91]}$ & TMS-79 & $\alpha$ & $\alpha$ & & $\beta$ & & $\beta$ & & $\beta$ & & & $\operatorname{Ir}: \beta$ \\
\hline Cadel et al. ${ }^{[92]}$ & N18 & $\alpha$ & $\beta$ & $\alpha$ & $\beta$ & & $\beta$ & $\beta$ & & & & \\
\hline Booth-Morrison et al. ${ }^{[43]}$ & $\mathrm{Ni}-\mathrm{Al}-\mathrm{Cr}-\mathrm{Ta}$ & $\alpha$ & $\beta *$ & & & & $\beta$ & & $\beta$ & & & \\
\hline Zhou et al. ${ }^{[93]}$ & $\mathrm{Ni}-\mathrm{Al}-\mathrm{Cr}-\mathrm{X}(\mathrm{X}=\mathrm{Re} / \mathrm{Ru})$ & $\alpha$ & $\beta$ & & & & $\beta$ & & & & & $\mathrm{Re}, \mathrm{Ru}: \beta$ \\
\hline Tu et al. ${ }^{[94]}$ & Ni-Al-Mo & $\alpha$ & & & $\beta$ & & $\beta$ & & & & & \\
\hline Tiley et $a{ }^{[95]}$ & René 88 & $\alpha$ & $\beta$ & $=$ & & & $\beta$ & $\beta$ & & & & \\
\hline Liu et al..$^{[96]}$ & $\mathrm{Ni}-\mathrm{Al}-\mathrm{X}(\mathrm{X}=\mathrm{Cr} / \mathrm{Co} / \mathrm{Ru})$ & $\alpha$ & $\beta$ & $=$ & & & $\beta$ & & & & & $\mathrm{Ru}: \beta$ \\
\hline Oni et al..$^{[97]}$ & $\mathrm{Ni}-\mathrm{Al}-\mathrm{Co}-\mathrm{Ti}$ & $\alpha$ & & $=$ & & & $\beta$ & $\beta$ & & & & \\
\hline Bagot et al..$^{[38]}$ & RR 1000 & $\alpha$ & $\alpha$ & $\alpha$ & $\beta *$ & & $\beta$ & $\beta$ & $\beta$ & $\beta$ & & \\
\hline
\end{tabular}

Results are compiled from APT studies on model alloys and commercial materials and are ordered chronologically. An asterisk symbol marks only a weak preference, while an equality sign denotes a lack of preference. 
Table IX. Site Preferences of Elements Within the $\gamma^{\prime}$ Phase, Expressed as the Percentage of Atoms Occupying Al $\beta$-Sublattice Sites, Predicted by Thermo-Calc and the TCNi8 and TTNi8 Databases

\begin{tabular}{|c|c|c|c|c|c|c|c|c|c|c|c|c|}
\hline \multirow[b]{2}{*}{ Alloy } & \multirow[b]{2}{*}{ Method } & \multicolumn{11}{|c|}{ Probability of Element on Al $\beta$-Sublattice Sites (Pct) } \\
\hline & & $\mathrm{Ni}$ & $\mathrm{Cr}$ & $\mathrm{Co}$ & Mo & W & $\mathrm{Al}$ & $\mathrm{Ti}$ & $\mathrm{Ta}$ & $\mathrm{Hf}$ & $\mathrm{Si}$ & $\mathrm{Fe}$ \\
\hline \multirow[t]{2}{*}{ SX1 } & TCNi8 & 0.19 & 68.63 & 6.92 & 93.88 & 95.21 & 96.05 & & 99.41 & & & 12.91 \\
\hline & TTNi8 & 0.31 & 52.59 & 0.24 & 91.69 & 90.19 & 99.25 & & 99.99 & & & 22.34 \\
\hline \multirow[t]{2}{*}{ SX2 } & TCNi8 & 0.16 & 69.07 & 8.91 & 93.13 & 94.85 & 96.30 & & 99.41 & 99.96 & & 13.23 \\
\hline & TTNi8 & 0.37 & 52.91 & 0.23 & 90.77 & 89.87 & 99.38 & & 99.98 & 99.67 & & 23.20 \\
\hline \multirow[t]{2}{*}{ SX3 } & TCNi8 & 0.11 & 58.54 & 5.19 & 88.66 & 89.75 & 94.11 & & 99.23 & & & 11.31 \\
\hline & TTNi8 & 0.16 & 36.00 & 0.12 & 85.84 & 82.19 & 98.59 & & 99.96 & & & 12.04 \\
\hline \multirow[t]{2}{*}{ SX4 } & TCNi8 & 0.12 & 60.15 & 0.91 & 85.75 & 89.60 & 98.11 & 99.84 & 98.96 & & & 12.16 \\
\hline & TTNi8 & 0.38 & 46.50 & 0.16 & 82.83 & 87.34 & 99.33 & 99.99 & 99.97 & & & 13.87 \\
\hline \multirow[t]{2}{*}{ SX5 } & TCNi8 & 0.12 & 62.78 & 5.53 & 94.48 & 95.16 & 94.88 & & 98.79 & & & 9.25 \\
\hline & TTNi8 & 0.25 & 46.99 & 0.20 & 90.12 & 89.88 & 99.18 & & 99.98 & & & 18.00 \\
\hline \multirow[t]{2}{*}{ SX6 } & TCNi8 & 0.21 & 72.21 & 8.72 & 94.70 & 95.87 & 96.91 & & 99.55 & 99.97 & 73.79 & 15.73 \\
\hline & TTNi8 & 0.39 & 58.74 & 0.31 & 92.47 & 91.23 & 99.46 & & 99.99 & 99.72 & 100.0 & 25.54 \\
\hline
\end{tabular}

Table X. Comparison of the Ratio of Nominal Cr and Co Contents in At. Pct to the Partitioning Coefficients of Hf and Si, $K_{\mathrm{Hf}}^{\gamma^{\prime} / \gamma}$ and $K_{\mathrm{Si}}^{\gamma^{\prime} / \gamma}$, for Several Trial and Commercial Superalloys Analyzed in APT Studies

\begin{tabular}{|c|c|c|c|c|c|c|}
\hline Study & Material & Cr (At. Pct) & Co (At. Pct) & Hf (At. Pct) & $\mathrm{Cr} / \mathrm{Co}$ & $K_{\mathrm{Hf}}^{\gamma^{\prime} / \gamma}$ \\
\hline \multirow[t]{2}{*}{ Amouyal et al..$^{[58,59]}$} & ME-9 & 8.18 & 7.74 & 0.05 & 1.06 & 0.14 \\
\hline & ME-15 & 7.73 & 7.31 & 0.05 & 1.06 & 0.16 \\
\hline Murakami et al. ${ }^{[89]}$ & CMSX-4 & 7.60 & 9.80 & 0.03 & 0.78 & $>1$ \\
\hline \multirow[t]{2}{*}{ Reed et al..$^{[98]}$} & RR2100 & 3.00 & 12.85 & 0.05 & 0.23 & 2.20 \\
\hline & RR2101 & 3.06 & 12.97 & 0.05 & 0.24 & 4.50 \\
\hline Yoon et al..$^{[78]}$ & René N6 & 4.96 & 12.96 & 0.05 & 0.38 & 4.75 \\
\hline Bagot et al. ${ }^{[38]}$ & RR1000 & 16.50 & 17.90 & 0.16 & 0.92 & $\approx 8$ \\
\hline Present work & SX2 & 13.26 & 4.86 & 0.34 & 2.73 & 51.91 \\
\hline Study & Material & Cr (At. Pct) & Co (At. Pct) & Si (At. Pct) & $\mathrm{Cr} / \mathrm{Co}$ & $K_{\mathrm{Si}}^{\gamma^{\prime} / \gamma}$ \\
\hline Segersäll et al. ${ }^{[73]}$ & STAL15SX & 17.87 & 4.90 & 0.53 & 3.65 & 0.33 \\
\hline Present work & SX6 & 13.22 & 4.44 & 1.05 & 2.98 & 0.60 \\
\hline \multirow[t]{2}{*}{ Yeh et al. ${ }^{[29]}$} & $\mathrm{KC}-4$ & 9.27 & 9.19 & 1.06 & 1.01 & 0.79 \\
\hline & $\mathrm{KC}-3$ & 9.32 & 9.25 & 0.53 & 1.01 & 0.82 \\
\hline \multirow[t]{2}{*}{ Yeh et al. ${ }^{[28]}$} & TMS-138A-Mo $+\mathrm{Si}$ & 3.90 & 6.20 & 1.00 & 0.63 & 1.54 \\
\hline & TMS-138A-Cr + Si & 2.90 & 6.20 & 1.00 & 0.47 & 1.54 \\
\hline
\end{tabular}

EPMA results for the Si-bearing alloys KC-3 and KC-4 are also included for better comparison. Table rows are arranged in an ascending order of $K_{\mathrm{Hf}}^{\gamma^{\prime} / \gamma}$ and $K_{\mathrm{Si}}^{\prime^{\prime} / \gamma}$ in the last column.

slower-diffusing solutes like Ta, W, or Re may preferentially segregate to $\gamma / \gamma^{\prime}$ interfaces, and this was indeed observed for the case of $\mathrm{Re}$ in several single-crystal superalloys. ${ }^{[75-79]}$ However, it was concluded that this enrichment does not simply arise for reasons of thermodynamic equilibrium, but rather that it is related to the growth of $\gamma^{\prime}$ precipitates during cooling ${ }^{[77,79]}$. Phase field modeling conclusively showed that the diffusion rate of $\mathrm{Re}$ is too slow to allow equilibrium particle growth and that, as the $\gamma / \gamma^{\prime}$ interfaces migrate during cooling, a Re 'bow wave' forms ahead of them. ${ }^{[77,79]}$ The same type of profile has also been reported for $\mathrm{W}$ segregation ${ }^{[39,61,62]}$ and is observed in the present work. Furthermore, W enrichment has only been observed at the interfaces of secondary, cuboidal precipitates, but not at the curved interfaces of tertiary, spheroidal precipitates. As the latter form during isothermal aging heat treatments, there is no comparable supersaturation as during cooling after the solutioning step that could give rise to interfacial segregation. All these considerations suggest that the excess $\mathrm{W}$ will no longer be present at interfaces during long-term creep exposure, as the alloy microchemistry will gradually approach an equilibrium state. Nonetheless, the higher molar fractions of $\mathrm{W}$ and Mo in the $\gamma$ phase of alloys like SX2, SX4, and SX5 are expected to increase creep resistance. As slow-diffusing atomic species, W and Mo have the beneficial effect of imposing a drag effect on dislocation movement, thus reducing the creep strain rate. ${ }^{[51,80,81]}$

\section{SUMMARY AND CONCLUSIONS}

A set of six trial IGT alloys combining high $\mathrm{Cr}$ and $\mathrm{Al}$ contents for optimized hot corrosion and high-temperature oxidation resistance has been investigated. 
Table XI. Summary of Reports on Solute Segregation at $\gamma / \gamma^{\prime}$ Interfaces

\begin{tabular}{|c|c|c|c|c|}
\hline Study & Material & W & $\mathrm{Re}$ & Segregation? \\
\hline Delargy and $\mathrm{Smith}^{[99]}$ & IN-939 & & & No \\
\hline Blavette and Bostel ${ }^{[82]}$ & CMSX-2 & $x$ & & Yes: $\mathrm{Cr}$ \\
\hline Blavette et al..$^{[83,100]}$ & ONERA alloy & & & No \\
\hline Hopgood and Martin ${ }^{[101,102]}$ & SRR99 & $x$ & & Yes: $\mathrm{Cr}$ \\
\hline Harada et al. ${ }^{[86]}$ & TMS-63 & & & No \\
\hline Duval et al. ${ }^{[87]}$ & $\mathrm{MC2}$ & $x$ & & Yes: $\mathrm{Cr}$ \\
\hline Miller et al. ${ }^{[88]}$ & PWA1480 & $x$ & & No \\
\hline Wanderka and Glatzel ${ }^{[75]}$ & CMSX-4 & $x$ & $x$ & Yes: Re \\
\hline Murakami et al..$^{[76]}$ & CMSX-4 & $x$ & $x$ & Yes: Re \\
\hline Murakami et al. ${ }^{[91]}$ & TMS-79 & & & No \\
\hline Warren et al. ${ }^{[77]}$ & RR3000 & $x$ & $x$ & Yes: Re \\
\hline Yoon et al. ${ }^{[78]}$ & René N6 & $x$ & $x$ & Yes: Re \\
\hline Reed et al. ${ }^{[98]}$ & RR2100 and RR2101 & $x$ & $x$ & No \\
\hline Tin et al. ${ }^{[103]}$ & $\mathrm{C} 17-1, \mathrm{C} 17-2, \mathrm{C} 17-3$ & $x$ & $x$ & Yes: Re, Co \\
\hline Amouyal et al. ${ }^{[61,62]}$ & ME-9 and ME-15 & $x$ & $x$ & Yes: W \\
\hline Mottura et al..$^{[79,104]}$ & CMSX-4 & $x$ & $x$ & Yes: Re \\
\hline Muraleedharan et al. ${ }^{[105]}$ & DMS4 & $x$ & $x$ & No \\
\hline Lapington et al. ${ }^{[39]}$ & ABD-2, ABD-4, ABD-6 & $x$ & & Yes: W \\
\hline Present work & $\mathrm{SX} 2, \mathrm{SX} 4, \mathrm{SX} 5$ & $x$ & & Yes: W \\
\hline
\end{tabular}

Results are compiled from APT studies on model alloys and commercial materials and are ordered chronologically. Cross marks indicate the presence of slow-diffusing W or Re in the material. Any elements observed to segregate are identified in the last column.

Extensive experimental analyses of alloy microstructure, phase transition temperatures, and phase microchemistry reveal a complex influence of composition on alloy properties and an intricate interaction between different elemental additions. Several general observations have been made:

1. The alloy microstructure is composed of cuboidal, secondary $\gamma^{\prime}$ precipitates and spherical, tertiary $\gamma^{\prime}$ particles, embedded in the $\gamma$ matrix. Thermo-Calc predictions for the equilibrium $\gamma^{\prime}$ volume fractions at $845^{\circ} \mathrm{C}$ are in good agreement with results from image analysis of SEM micrographs.

2. Thermo-Calc predictions for $\gamma^{\prime}$ solvus and solidus temperatures are in reasonable agreement with DSC experimental results. For alloys without $\mathrm{Hf}$, the span of the HTW can be estimated to within $20^{\circ} \mathrm{C}$ by combining the $\gamma^{\prime}$ solvus from TTNi8 and the solidus from TCNi8.

3. As revealed through APT analyses, slight changes in chemistry can have profound effects on alloy microchemistry. Thermo-Calc predictions for phase compositions using both TCNi8 and TTNi8 consistently underestimate $K_{\mathrm{Ni}}^{\gamma^{\prime}} / \gamma, K_{\mathrm{Mo}}^{\gamma^{\prime} / \gamma}, K_{\mathrm{W}}^{\gamma^{\prime} / \gamma}$, and $K_{\mathrm{Al}}^{\gamma^{\prime} / \gamma}$, while overestimating $K_{\mathrm{Cr}}^{\gamma / \gamma}$. It is imperative to adjust and update thermodynamic database parameters for this region of the alloy design space if CALPHAD methods are to provide reliable and accurate inputs for alloy design tools.

4. Proxigram analyses across $\gamma / \gamma^{\prime}$ interfaces reveal a diffuse, non-uniform transition between plateau concentrations over several $\mathrm{nm}$. The average width of interfacial profiles correlates well with the atomic size difference between the respective element and $\mathrm{Ni}$, as described by the empirical Vegard coefficients.
5. $\gamma / \gamma^{\prime}$ lattice misfit values estimated using phase compositions determined by APT and empirical relations are in good agreement with the observed changes in precipitate morphology. The particle shape becomes increasingly rounded as the absolute value of misfit decreases. Misfit estimates based on CALPHAD predictions of the molar volumes of $\gamma$ and $\gamma^{\prime}$ phases are inaccurate.

Furthermore, several guidelines and recommendations for IGT alloy design within the compositional space considered here can be drawn:

1. Elements restricting the available HTW such as Hf, $\mathrm{Ti}$, and Si must be carefully controlled to allow a full microstructural homogenization. This has been achieved in the present work using an optimized solutioning heat treatment with a constant temperature ramp in the HTW regime.

2. Elements with a preference for the Al $\beta$-sublattice like $\mathrm{Ta}, \mathrm{Ti}$, and $\mathrm{Hf}$ are effective at displacing slow-diffusing solutes such as W and Mo from these sites and into the $\gamma$ matrix. This effect is expected to increase creep resistance, as the higher molar fractions of $\mathrm{W}$ and $\mathrm{Mo}$ in the matrix will help reduce the rate of diffusion-controlled dislocation movement.

3. An enrichment of $\mathrm{W}$ at $\gamma / \gamma^{\prime}$ interfaces is only found in alloys with $K_{\mathrm{W}}^{\gamma^{\prime} / \gamma}<1$, in agreement with the literature. It results from the growth of secondary $\gamma^{\prime}$ particles under non-equilibrium conditions during cooling after the solutioning step. The W 'bow wave' formed ahead of the precipitates is expected to dissipate during high-temperature service and will not impart additional creep strengthening. 
4. The partitioning behaviors of $\mathrm{Hf}$ and $\mathrm{Si}$ may be influenced by the ratio of $\mathrm{Cr}$ and $\mathrm{Co}$ additions. At a low $\mathrm{Cr} / \mathrm{Co}$ ratio, it is anticipated that $\mathrm{Co}$ will stabilize the $\gamma^{\prime}$ phase for $\mathrm{Hf}$ or $\mathrm{Si}$, whereas at a high $\mathrm{Cr} / \mathrm{Co}$ ratio, $\mathrm{Cr}$ may increase the solubility of $\mathrm{Hf}$ or $\mathrm{Si}$ in the $\gamma$ matrix and reverse partitioning. However, this trend does not extend to higher $\mathrm{Hf}$ contents, for which Hf is found to partition preferentially to $\gamma^{\prime}$ regardless of a high $\mathrm{Cr} / \mathrm{Co}$ ratio.

5. The interactions of Co with other elements and its influence on microchemistry have not yet been fully understood and warrant further investigations. The effects of Co depend on the overall chemical composition and on the selected heat treatment steps. For the alloy design space considered here, increasing the Co level has a beneficial effect of widening the HTW and of promoting the partitioning of $\mathrm{W}$ and Mo towards $\gamma$.

6. $\mathrm{Fe}$ additions have a similar effect to $\mathrm{Co}$ and significantly widen the HTW by depressing the $\gamma^{\prime}$ solvus. However, this also leads to a marked reduction in $\gamma^{\prime}$ volume fraction, which is expected to negatively impact high-temperature mechanical properties. Therefore, $\mathrm{Fe}$ additions for improved oxidation resistance must be carefully considered against possible detrimental effects.

\section{ACKNOWLEDGMENTS}

Financial support and material provision from Siemens Industrial Turbomachinery $\mathrm{AB}$ are acknowledged gratefully. The authors would like to thank Nils Ritter from the Friedrich-Alexander-University Erlangen-Nürnberg for manufacturing the alloys and Chris Salter from Oxford Materials Characterisation Service for carrying out EPMA analyses. PB and MM acknowledge financial support from the Engineering and Physical Sciences Research Council (EPSRC) under grant number EP/M022803/1, while RR acknowledges financial support from the EPSRC under grant number EP/M005607/1. The collaboration with HM at NIMS was supported by a Research Fellowship for SS from the Japan Society for the Promotion of Science (JSPS).

\section{OPEN ACCESS}

This article is licensed under a Creative Commons Attribution 4.0 International License, which permits use, sharing, adaptation, distribution and reproduction in any medium or format, as long as you give appropriate credit to the original author(s) and the source, provide a link to the Creative Commons licence, and indicate if changes were made. The images or other third party material in this article are included in the article's Creative Commons licence, unless indicated otherwise in a credit line to the material. If material is not included in the article's Creative Commons licence and your intended use is not permitted by statutory regulation or exceeds the permitted use, you will need to obtain permission directly from the copyright holder. To view a copy of this licence, visit http://creat ivecommons.org/licenses/by/4.0/.

\section{REFERENCES}

1. T.M. Pollock: Nat. Mater., 2016, vol. 15, pp. 809-15.

2. B.B. Seth: in Superalloys 2000, T.M. Pollock, K. Green, and R. Kissinger, eds., TMS, Warrendale, PA, 2000, pp. 3-16.

3. C.G. Bieber and J.J. Galka: Cast nickel-base alloy, 1971. US3619182.

4. J. Hockin, C.H. Lund, and M.J. Woulds: High temperature castable alloys and castings, 1972, US3677747.

5. R.C. Reed, J. Moverare, A. Sato, F. Karlsson, and M. Hasselqvist: in Superalloys 2012, E.S. Huron, R.C. Reed, M.C. Hardy, M.J. Mills, R.E. Montero, P.D. Portella, and J. Telesman, eds., Wiley, New York, 2012, pp. 197-204.

6. A. Sato, J.J. Moverare, M. Hasselqvist, and R.C. Reed: Metall. Mater. Trans. A, 2012, vol. 43A, pp. 2302-15.

7. S. Sulzer, E. Alabort, A. Németh, B. Roebuck, and R. Reed: Metall. Mater. Trans. A, 2018, vol. 49A, pp. 4214-35.

8. P. Kontis, H.M. Yusof, S. Pedrazzini, M. Danaie, KL. Moore, P. Bagot, M.P. Moody, C. Grovenor, and R.C. Reed: Acta Mater., 2016, vol. 103, pp. 688-99.

9. P. Kontis, E. Alabort, D. Barba, D.M. Collins, A.J. Wilkinson, and R.C. Reed: Acta Mater., 2017, vol. 124, pp. 489-500.

10. H. Harada and H. Murakami: in Computational Materials Design, A. Zunger, R.M. Osgood, R. Hull, H. Sakaki, and T. Saito, eds., Springer Series in Materials Science, vol. 34, Springer, Berlin, 1999, pp. 39-70.

11. R.C. Reed, T. Tao, and N. Warnken: Acta Mater., 2009, vol. 57, pp. 5898-5913.

12. R.C. Reed, Z. Zhu, A. Sato, and D.J. Crudden: Mater. Sci. Eng. $A$, 2016, vol. 667, pp. 261-78.

13. R.C. Reed, A. Mottura, D.J. Crudden, in Superalloys 2016, M.C. Hardy, E.S. Huron, U. Glatzel, B. Griffn, B. Lewis, C. Rae, V. Seetharaman, and S. Tin, eds., Wiley, Hoboken, 2016, pp. 13-23.

14. D.J. Crudden, B. Raeisinia, N. Warnken, and R.C. Reed: Metall. Mater. Trans. A, 2013, vol. 44A, pp. 2418-30.

15. S.R. Hegde, R.M. Kearsey, and J.C. Beddoes: Mater. Sci. Eng. $A$, 2010, vol. 527, pp. 5528-38.

16. J.J. Friel, J.C. Grande, D.W. Hetzner, K.J. Kurzydłowski, D. Laferty, M.T. Shehata, V. Smolej, G.F. Vander Voort, and L. Wojnar: Practical Guide to Image Analysis, ASM International, Materials Park, OH, 2000.

17. K.C. Mills, Y.M. Youssef, and Z. Li: ISIJ Int., 2006, vol. 46, pp. $50-57$.

18. P.N. Quested, R.F. Brooks, L. Chapman, R. Morrell, Y. Youssef, and K.C. Mills: Mater. Sci. Technol., 2009, vol. 25, pp. $154-62$

19. D.L. Sponseller, in Superalloys 1996, R.D. Kissinger, D.J. Deye, D.L. Anton, A.D. Cetel, M.V. Nathal, and T.M. Pollock, eds., TMS, Warrendale, PA, 1996, pp. 259-70.

20. L.A. Chapman: J. Mater. Sci., 2004, vol. 39, pp. 7229-36.

21. C.J. Burton: in Superalloys: Metallurgy and Manufacture, B.H. Kear, ed., Claitor, 1976, pp. 147-57.

22. J. Zhang and R.F. Singer: Metall. Mater. Trans. A, 2004, vol. 35 A, pp. $1337-42$

23. P.S. Kotval, J.D. Venables, and R.W. Calder: Metall. Trans., 1972, vol. 3, pp. 457-62.

24. M.V. Nathal and L.J. Ebert: Metall. Trans. A, 1985, vol. 16, pp. $1849-62$.

25. J. Zhang and R.F. Singer: Acta Mater., 2002, vol. 50, pp. 1869-79.

26. J. Zhang: in Superalloys 2004, K. Green, H. Harada, and T.M. Pollock, eds., TMS, Warrendale, PA, 2004, pp. 727-33.

27. R.V. Miner: Metall. Trans. A, 1977, vol. 8, pp. 1949-54

28. A.C. Yeh, K. Kawagishi, H. Harada, T. Yokokawa, Y. Koizumi, T. Kobayashi, D.H. Ping, J. Fujioka, and T. Suzuki, in Superalloys 2008, R.C. Reed, K.A. Green, P. Caron, T. Gabb, M.G. 
Fahrmann, E.S. Huron, and S.A. Woodward, eds., TMS, Warrendale, PA, 2008, pp. 619-28.

29. A.C. Yeh, K.C. Yang, J.W. Yeh, and C.M. Kuo: J. Alloys Compd., 2014, vol. 585, pp. 614-21.

30. J.K. Tien, T.E. Howson, G.L. Chen, and X.S. Xie: JOM, 1980, vol. 32, pp. 12-20.

31. R.N. Jarrett and J.K. Tien: Metall. Trans. A, 1982, vol. 13, pp. 1021-32.

32. R.N. Jarrett, J.P. Collier, and J.K. Tien, in Superalloys 1984, M. Gell, C.S. Kortovich, and R.H. Bricknell, eds., TMS, Warrendale, PA, 1984, pp. 455-66.

33. F.H. Harf: Metall. Trans. A, 1985, vol. 16, pp. 993-1003.

34. M.V. Nathal, R.D. Maier, and L.J. Ebert: Metall. Trans. A, 1982, vol. 13, pp. 1775-83.

35. S. Llewelyn, K.A. Christofidou, V.J. Araullo-Peters, N.G. Jones, M.C. Hardy, E.A. Marquis, and H.J. Stone: Acta Mater., 2017, vol. 131 , pp. 296-304.

36. I.M. Allam: Oxid. Met., 2009, vol. 72, pp. 127-44

37. M.K. Miller, S.S. Babu, and M.G. Burke: Mater. Sci. Eng., 2002, vol. 327 , pp. 84-88.

38. P. Bagot, O. Silk, JO. Douglas, S. Pedrazzini, D.J. Crudden, T.L. Martin, M.C. Hardy, M.P. Moody, and R.C. Reed: Acta Mater., 2017, vol. 125, pp. 156-65.

39. M.T. Lapington, D.J. Crudden, R.C. Reed, M.P. Moody, and P.A.J. Bagot: Metall. Mater. Trans. A, 2018, vol. 351A, p. 419.

40. Y. Zhou, D. Isheim, G. Hsieh, R.D. Noebe, and D.N. Seidman: Philos. Mag., 2013, vol. 93, pp. 1326-50.

41. P. Caron, in Superalloys 2000, T.M. Pollock, K. Green, and R. Kissinger, eds., TMS, Warrendale, PA, 2000, pp. 737-46.

42. C. Booth-Morrison, R.D. Noebe, and D.N. Seidman: in Superalloys 2008, R.C. Reed, K.A. Green, P. Caron, T. Gabb, M.G. Fahrmann, E.S. Huron, and S.A. Woodward, eds., TMS, Warrendale, PA, 2008, pp 73-79.

43. C. Booth-Morrison, Z. Mao, RD. Noebe, and DN. Seidman: Appl. Phys. Lett., 2008, vol. 93, p. 033103.

44. C. Booth-Morrison, R.D. Noebe, and D.N. Seidman: Acta Mater., 2009, vol. 57, pp. 909-20.

45. Y. Mishima, S. Ochiai, and T. Suzuki: Acta Metall., 1985, vol. 33, pp. 1161-69.

46. P. Nash: Phase Diagrams of Binary Nickel Alloys, ASM International, Materials Park, OH, 1991.

47. A.B. Kamara, A.J. Ardell, and C.N.J. Wagner: Metall. Mater. Trans Actions A, 1996, vol. 27, pp. 2888-96.

48. R.A. Ricks, A.J. Porter, and R.C. Ecob: Acta Metall., 1983, vol. 31 , pp. $43-53$.

49. M. Doi, T. Miyazaki, and T. Wakatsuki: Metall. Trans. A, 1984, vol. 67, pp. 247-53.

50. A.J. Goodfellow, E.I. Galindo-Nava, K.A. Christofidou, N.G. Jones, C.D. Boyer, T.L. Martin, P. Bagot, M.C. Hardy, and H.J. Stone: Acta Mater., 2018, vol. 153, pp. 290-302.

51. S. Sulzer and R. Reed: Mater. Sci. Technol., 2018, vol. 8, pp. $1-28$.

52. D.N. Duhl and C.P. Sullivan: JOM, 1971, vol. 23, pp. 38-40.

53. J.M. Dahl, W.F. Danesi, and R.G. Dunn: Metall. Trans., 1973, vol. 4, pp. 1087-96.

54. V.K. Tolpygo, K.S. Murphy, and D.R. Clarke: Acta Mater., 2008, vol. 56, pp. 489-99.

55. S. Hayashi and B. Gleeson: Oxid. Met., 2009, vol. 71, pp. 5-19.

56. P. Speck and D.J. Young: Oxid. Met., 2011, vol. 76, pp. 287-305.

57. Y. Amouyal and D.N. Seidman: Acta Mater., 2011, vol. 59, pp. 6729-42.

58. Y. Amouyal, Z. Mao, and D.N. Seidman: Appl. Phys. Lett., 2009, vol. 95 , p. 161909.

59. Y. Amouyal and D.N. Seidman: Acta Mater., 2011, vol. 59, pp. 3321-33.

60. Y. Amouyal, Z. Mao, C. Booth-Morrison, and D.N. Seidman: Appl. Phys. Lett., 2009, vol. 94, p. 041917.

61. Y. Amouyal, Z. Mao, and D.N. Seidman: Acta Mater., 2010, vol. 58 , pp. $5898-5911$.

62. Y. Amouyal, Z. Mao, and D.N. Seidman: Acta Mater., 2014, vol. 74, pp. 296-308.

63. M. Pröbstle, S. Neumeier, P. Feldner, R. Rettig, H.E. Helmer, R.F. Singer, and M. Göken: Mater. Sci. Eng. A, 2016, vol. 676, pp. 411-20.
64. N.C. Ritter, E. Schesler, A. Muüller, R. Rettig, C. Körner, and R.F. Singer: Adv. Eng. Mater., 2017, vol. 19, p. 1700150.

65. S.W. Yang: Oxid. Met., 1981, vol. 15, pp. 375-97.

66. C.A. Barrett, R.V. Miner, and D.R. Hull: Oxid. Met., 1983, vol. 20, pp. 255-78.

67. R.J. Bennett, R. Krakow, A.S. Eggeman, C.N. Jones, H. Murakami, and C. Rae: Acta Mater., 2015, vol. 92, pp. 278-89.

68. Y. Zhi'an, X. Yaotian, and S. Changxu: Mater. Sci. Eng., 1988, vol. 101, pp. 65-73.

69. S. Ochiai, Y. Oya, and T. Suzuki: Acta Metall., 1984, vol. 32, pp. 289-98.

70. J.R. Nicholls and R.D. Rawlings: Acta Metall., 1977, vol. 25, pp. 187-94.

71. M.K. Miller and J.A. Horton: Scr. Metall., 1986, vol. 20, pp. $1125-30$.

72. A. Sato, Y.-L. Chiu, and R.C. Reed: Acta Mater., 2011, vol. 59, pp. $225-40$.

73. M. Segersäll, P. Kontis, S. Pedrazzini, P.A. Bagot, M.P. Moody, J.J. Moverare, and R.C. Reed: Acta Mater., 2015, vol. 95, pp. 456-67.

74. Y. Amouyal, Z. Mao, and D.N. Seidman: Appl. Phys. Lett., 2008, vol. 93, p. 201905.

75. N. Wanderka and U. Glatzel: Mater. Sci. Eng., 1995, vol. 203, pp. 69-74.

76. H. Murakami, Y. Saito, and H. Harada, in Superalloys 1996, R.D. Kissinger, D.J. Deye, D.L. Anton, A.D. Cetel, M.V. Nathal, and T.M. Pollock, eds., TMS, Warrendale, PA, 1996, pp. 249-57.

77. P. Warren, A. Cerezo, and G. Smith: Mater. Sci. Eng., 1998, vol. 250 , pp. $88-92$.

78. K.E. Yoon, D. Isheim, R.D. Noebe, and D.N. Seidman: Interface Sci., 2001, vol. 9, pp. 249-55.

79. A. Mottura, N. Warnken, M.K. Miller, M.W. Finnis, and R.C. Reed: Acta Mater., 2010, vol. 58, pp. 931-42.

80. E. Fleischmann, M.K. Miller, E. Affeldt, and U. Glatzel: Acta Mater., 2015, vol. 87, pp. 350-56.

81. X. Wu, S.K. Makineni, C.H. Liebscher, G. Dehm, J. Rezaei Mianroodi, P. Shanthraj, B. Svendsen, D. Bürger, G. Eggeler, D. Raabe, and B. Gault: Nat. Commun., 2020, vol. 11, p. 389.

82. D. Blavette and A. Bostel: Acta Metall., 1984, vol. 32, pp. 811-16.

83. D. Blavette, A. Bostel, and J.M. Sarrau: Metall. Trans. A, 1985, vol. 16, pp. 1703-11.

84. D. Blavette, P. Caron, and T. Khan, in Superalloys 1988, S. Reichman, D.N. Duhl, G.E. Maurer, S.D. Antolovich, and C. Lund, eds., TMS, Warrendale, PA, 1988, pp. 305-14.

85. K.L. More, M.K. Miller: Le Journal de Physique Colloques, 1988, vol. 49, pp. C6-391-C6-396

86. H. Harada, A. Ishida, Y. Murakami, H. Bhadeshia, and M. Yamazaki: Appl. Surf. Sci., 1993, vol. 67, pp. 299-304.

87. S. Duval, S. Chambreland, P. Caron, and D. Blavette: Acta Metall. Mater., 1994, vol. 42, pp. 185-94.

88. M. Miller, R. Jayaram, L. Lin, and A. Cetel: Appl. Surf. Sci., 1994, vols. 76-77, pp. 172-76.

89. H. Murakami, H. Harada, and H. Bhadeshia: Appl. Surf. Sci., 1994, vols. 76-77, pp. 177-83.

90. R. Jayaram and M.K. Miller: Acta Metall. Mater., 1995, vol. 43, pp. 1979-86.

91. H. Murakami, Y. Koizumi, T. Yokokawa, Y. Yamabe-Mitarai, T. Yamagata, and H. Harada: Mater. Sci. Eng., 1998, vol. 250, pp. 109-14.

92. E. Cadel, D. Lemarchand, S. Chambreland, and D. Blavette: Acta Mater., 2002, vol. 50, pp. 957-66.

93. Y. Zhou, Z. Mao, C. Booth-Morrison, and D.N. Seidman: Appl. Phys. Lett., 2008, vol. 93, p. 171905.

94. Y. Tu, Z. Mao, and D.N. Seidman: Appl. Phys. Lett., 2012, vol. 101, p. 121910.

95. J.S. Tiley, O. Senkov, G. Viswanathan, S. Nag, J. Hwang, and R. Banerjee: Metall. Mater. Trans. A, 2013, vol. 44, pp. 31-38.

96. S.H. Liu, C.P. Liu, W.Q. Liu, X.N. Zhang, P. Yan, and C.Y. Wang: Philos. Mag., 2016, vol. 96, pp. 2204-18.

97. A.A. Oni, S.R. Broderick, K. Rajan, and J.M. LeBeau: Intermetallics, 2016, vol. 73, pp. 72-78. 
98. R.C. Reed, A.C. Yeh, S. Tin, S.S. Babu, and M.K. Miller: Scr. Mater., 2004, vol. 51, pp. 327-331.

99. K.M. Delargy and G.D.W. Smith: Metall. Trans. A, 1983 , vol. 14, pp. 1771-83.

100. D. Blavette and A. Bostel: Surf. Sci., 1986, vol. 177, pp. L994-98.

101. A. Hopgood and J. Martin: Mater. Sci. Eng., 1986, vol. 82, pp. 27-36.

102. A.A. Hopgood, A. Nicholls, G.D.W. Smith, and J.W. Martin: Mater. Sci. Technol., 1988, vol. 4, pp. 146-52.

103. S. Tin, L. Zhang, G. Brewster, and M.K. Miller: Metall. Mater. Trans. A, 2006, vol. 37, pp. 1389-96.
104. A. Mottura, M.K. Miller, and R.C. Reed, in Superalloys 2008, R.C. Reed, K.A. Green, P. Caron, T. Gabb, M.G. Fahrmann, E.S. Huron, and S.A. Woodward, eds., TMS, Warrendale, PA, 2008, pp. 891-900.

105. K. Muraleedharan, R. Balamuralikrishnan, and N. Das: $J$. Mater. Sci., 2009, vol. 44, pp. 2218-25.

Publisher's Note Springer Nature remains neutral with regard to jurisdictional claims in published maps and institutional affiliations. 